\title{
Factors Impacting Youth Development in Haiti
}

By

\author{
Michael Justesen and Dorte Verner
}

World Bank ${ }^{1}$

\begin{abstract}
Of the 1.6 million Haitian youth aged 15-24, only 13 percent are content with their lives. More than half of 20-year-olds have not completed secondary education and nearly half of youth in the labor market are unemployed. This paper investigates protective and risk factors predisposing youth to positive and negative behaviors. These factors, including poverty, gender, education, labor market, migration, family, health, and violence, are examined by the use of statistics and probability models based on Haiti's first household living conditions survey. Key findings show that female youth need special attention because they are more likely than their male peers to drop out of school and to be unemployed or inactive. Role models, guidance, expectations, and contacts in the form of parents or household heads are decisive factors in keeping youth in school and to some extent in their finding employment. In addition, domestic migration has a positive impact on the probability of being employed and inactive (positive self-selection), while marriage, drug abuse, and domestic violence increase the probability of dropping out of school.
\end{abstract}

Keywords: Youth at risk, risk and protective factors, education, labor market, household survey, probability model.

World Bank Policy Research Working Paper 4110, January 2007

The Policy Research Working Paper Series disseminates the findings of work in progress to encourage the exchange of ideas about development issues. An objective of the series is to get the findings out quickly, even if the presentations are less than fully polished. The papers carry the names of the authors and should be cited accordingly. The findings, interpretations, and conclusions expressed in this paper are entirely those of the authors. They do not necessarily represent the view of the World Bank, its Executive Directors, or the countries they represent. Policy Research Working Papers are available online at http://econ.worldbank.org.

\footnotetext{
${ }^{1}$ We are grateful to Susanna Shapiro for helpful comments and Willy Egset for support with the household dataset.
} 


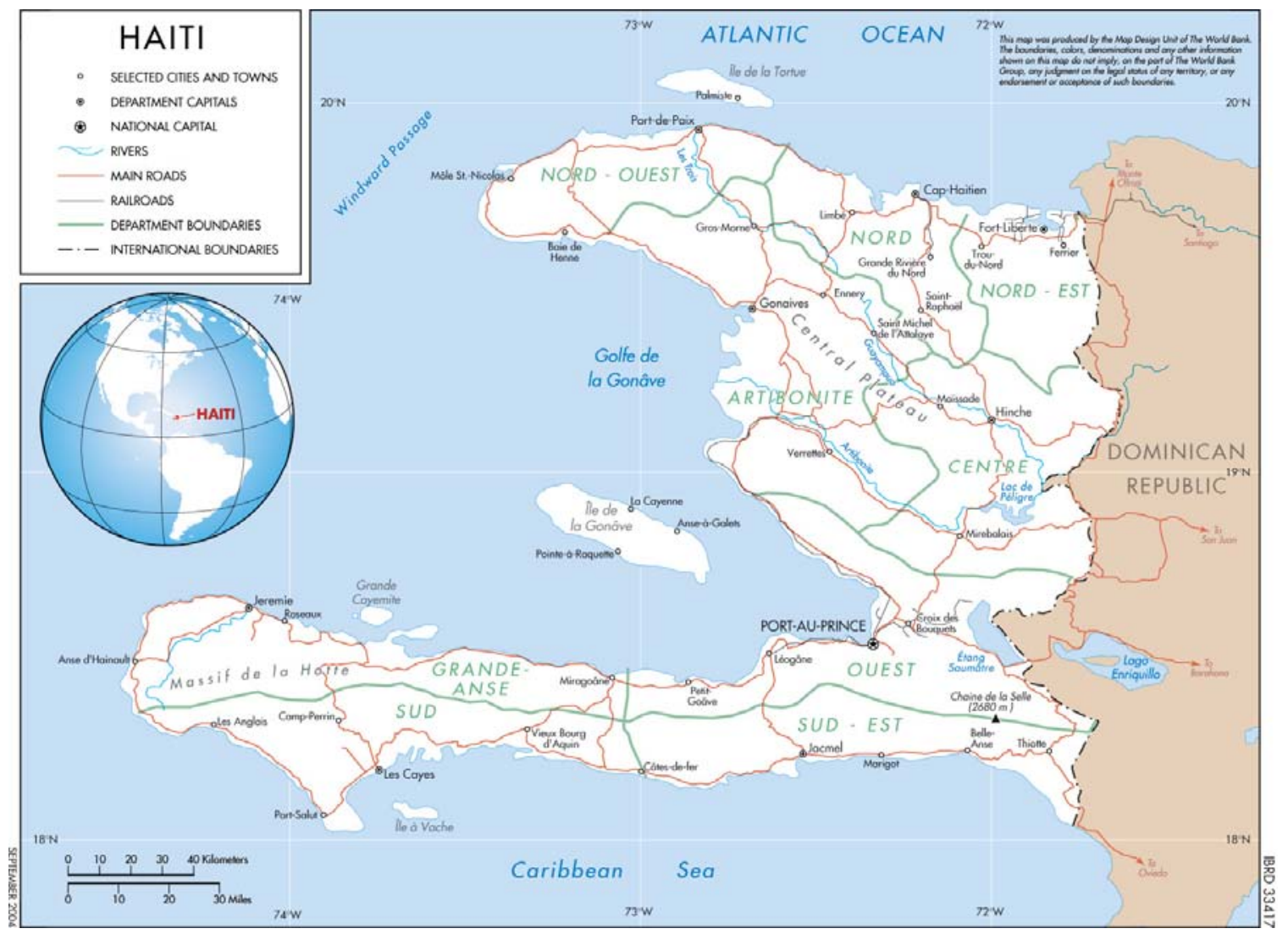




\section{Introduction}

Youth represent a large proportion of human capital in developing countries. Some attend school, participate in social and cultural events, enjoy support from their families, and have plans and hopes for their future while others do not. In Haiti, only 13 percent of youth feel satisfied with their lives, according to data from ECVH in 2001. ${ }^{2}$ A series of factors predisposes a large proportion of youth to poverty, school dropout, unemployment, early sexual initiation, teenage pregnancy, HIV/AIDS, sexual and physical abuse, crime and violence, substance abuse and drug dealing, and social exclusion. ${ }^{3}$ Indicators for Haiti on most of these factors are among the poorest in the Latin American and Caribbean region (LAC) and some are worse than those of African countries with the same level of GDP per capita (World Bank 2002). Dictatorship, military intervention, and lack of stability have been determining factors in Haiti's social and economic development history. Haiti's history, combined with the country's social and poverty indicators, show that youth should be seen not as a problem, but as a product of the family and community environment and therefore should be treated as a potential solution to Haiti's development challenges.

Data reveal that over 20 percent of the Haitian population is between 15 and 24 years old and 49 percent of households live in extreme poverty. Poor households contain more youth than average and youth are overrepresented in the capital city of Port-auPrince. The public education system, where in place, and many private schools, supply low quality education, and corporal punishment is widely used. Illiteracy rates are high and many young people are not in school because they need to contribute to household income or work in the household. Nearly half of Haitian youth are not enrolled in school and of those participating in the labor market, 47.4 percent are unemployed, the highest proportion in LAC. In particular, young women experience high unemployment and inactivity rates and often face wage discrimination. One way of coping with unemployment and lack of opportunities is for youth to migrate, either abroad or to another region or city in Haiti.

In many households absence of the father or both parents, drug abuse, pressure for female adolescents to bear children, and domestic violence contribute to the challenges young people face on a daily basis. For example, only one in three children (aged 0-14) in Haiti lives with both biological parents. The lack of health services, information, family counseling, etc., is negatively affecting youth health. ${ }^{4}$ Contraceptive use is among the lowest in the Western Hemisphere and HIV/AIDS has reached epidemic levels-the highest incidence outside Africa. Of the age group 15-19 years old, 5.2 percent has HIV/AIDS. However, there are clear indications that the situation is now improving and Haiti has been recognized for its progress in scaling up treatment. Teenage pregnancies

\footnotetext{
${ }^{2}$ ECVH is the first Living Conditions Survey of Haiti. See data description below.

${ }^{3}$ Social exclusion refers to lack of financial means, unequal access to human capital building services, unequal access to labor markets and public service and social protection programs (both in formal and informal institutions), and unequal political rights (World Bank 2003).

4 Overall, performance of health systems in Haiti is ranked lowest in LAC and 138th of 191 countries by the World Health Organization (World Bank 2002).
} 
and HIV/AIDS disproportionately affect youth from low-income families. Moreover, teenage mothers account for 8 percent of all births and contribute to Haiti's high fertility rate of 4.2 children per woman in $2003 .^{5}$

Violence is part of everyday life in Haiti. Aggressive behavior is frequently linked to the inability to meet social expectations or provide for the family, which many youth experience (e.g., Moser and Bronkhorst 1999). Most females in Haiti have experienced some form of violence. Sexual abuse of girls is highly prevalent: 46 percent of all girls have been abused (World Bank 2002). Of these victims, 33 percent were girls aged 5-9, and 43 percent were girls aged 10-14. In Haiti a blind eye is often turned to such issues as incest and domestic violence.

This paper identifies groups of Haitian youth in which the prevalence of risktaking behavior is high and accounts for why such behavior is observed. Little research has been done on Haiti in this area, likely because of lack of data. The paper refers to earlier research, but is mainly based on information extracted from a still unreleased household survey from 2001. The survey is the first Living Conditions Survey (ECVH) for Haiti and consists of 7,186 households including 33,007 individuals. The data set covers the entire country and is representative at the regional level. The paper is organized in seven sections. Section 2 describes the connection between protective and risk factors and outcomes and presents the general framework used to evaluate the situation for youth in Haiti. Section 3 gives an overview of demographics and income poverty. Section 4 examines education and the likelihood of youth not being in school, and labor markets and the likelihood of being unemployed or inactive; it also considers migration. Section 5 addresses family structures and health issues such as HIV/AIDS and teen pregnancy. Section 6 describes the security situation including crime, violence, domestic violence, and drug abuse. Section 7 concludes the paper and gives suggestions for future research. The appendix outlines a range of possible programs that could improve the situation for youth in Haiti.

\section{Framework}

The definition of youth varies depending on the context; it may be determined in relation to the developmental stage as the proportion of same-age youth enrolled in school or the proportion working. Such definitions show great variation at country or regional level in respect to defining youth as a certain age group. The age group used here is 15-24 years, which is the United Nations' definition. The use of this age group is in line with other studies in LAC (e.g., World Bank 2005e) and necessary because of data availability. Nevertheless, it is important to bear in mind that a clearly defined age group used to identify youth is merely a proxy for a stage in a young person's life. The transition from dependence (childhood) to independence (adulthood) involves challenges in connection with moving from school to labor market, moving from the parents' household to a new household and establishing close relationships outside the family

\footnotetext{
${ }^{5}$ World Development Indicators 2005.
} 
(e.g., getting married or having children [World Bank 2005e]). It is a transition period characterized by psychological change, and by development and maturation of personality and identity. During the period youth become part of alliances, but also strive for independence, for instance by obtaining economic security. Values and attitudes are developed, and important decisions are made that affect earning potential by choice of education, for example (Moser and Bronkhorst 1999). Thus, the beginning and end of the transition period from child to adult varies from one individual to another, a variation not accounted for in this paper.

The focus of this paper is youth at risk in Haiti. Youth at risk include those facing environmental, social, and family conditions that hinder personal development and successful transition into society and the economy.

\section{Risk and Protective Factors}

The framework to address youth at risk used in this paper is an ecological framework widely used in the health literature that reflects the linkages between youth and their environment in the form of family, community, state, etc. by considering the connection between risk and protective factors and youth and adult outcomes. The assumption underlying this framework is that various risk and protective factors early in life build an individual's preferences, expectations, evaluation, and responsibilities, and establish an understanding of the person's place in and way of interacting with society. Risk factors may expose youth to risk-taking behavior that compromise well-being and hinder personal development. Such behavior includes school dropout or early (unprotected) sexual initiation. Counterbalancing the risk factors are protective factors that mediate risk, such as a high level of completed education and employment, and act as protective mechanisms that insulate youth from negative effects (Fitzpatrick 1997).

In the transition from childhood to adulthood some youth will undertake risktaking behavior, which carries a risk of negative outcomes that decrease the likelihood of a happy and healthy life both as youth and adult ${ }^{6}$ (World Bank 2005a, 2003). Risk-taking behavior early in life is likely to have negative impacts on the ability of youth to handle stressful experiences later in life and may lead to destructive or antisocial behavior (Barker and Fontes 1996). For example, early unprotected sexual activity may lead to HIV/AIDS infection. Youth at risk are more likely than other youth to engage in such risky activities.

One way of associating risk and protective factors and their potential outcomes is to consider development as taking place in three overlapping spheres (World Bank 2005a, 2003, Fitzpatrick 1997): (1) at the individual level youth who are disadvantaged, e.g., by lack of life skills or self-esteem, are more likely to engage in risk-taking behaviors. In contrast, intelligence, self-confidence, and strong coping skills protect

\footnotetext{
${ }^{6}$ Negative outcomes can also be risk factors themselves. For example, school dropout can be a negative outcome of poverty, but may also be a risk factor since low human capital may predispose youth to early unprotected sexual activity or unemployment.
} 
youth from such behaviors; (2) the micro environment includes institutions and individuals with which youth interact personally, i.e., family, school, social networks, and role models. For example, family is the earliest and most enduring influence on the socialization of youth. Family disorganization, lack of family cohesion, and poor parental or adult supervision all present major risk factors for youth. An example of a predictor of risk-taking behavior in connection with school is academic failure. Such failure may be the onset of antisocial behavior and lead to a downward spiral. Social networks and guidance act as protective factors, but clearly established rules and expectations among others are also important in building resiliency and reducing the likelihood of engaging in risky behaviors; (3) the macro environment, which is the economy, inequality, institutions, social norms, sociodemographic differences such as gender and race, and the cultural and historical background, has a critical influence on youth. For example, if this environment is unsafe or uncertain, the likelihood of engaging in risky behaviors increases. The macro environment can also be a protective factor by providing job opportunities and social services.

The framework used in this paper reflects the problematic factors youth may encounter through the transition from childhood to adulthood. Instead of only considering evident signs of direct failures, such as youth committing robbery or using drugs, earlier phases of negative transitions are also identified. Such negative transitions may be observed as school dropout or push out or generally poor financial conditions. Using this framework it is possible to target key remediation points and more importantly key prevention points for youth at risk in Haiti. The following section will outline the general demographic and economic situation in Haiti and sections 4 to 6 will address the more specific situation for youth in order to identify certain groups at risk (the appendix outlines a number of possible intervention and remediation points).

\section{Lay of the Land}

\section{Demographics}

One out of five Haitians are between 15 and 24 years old and thereby categorized as youth for the purpose of this paper (see Figure 3.1). Compared to OECD countries, such as France and USA with respectively 13 and 14 percent of the population being youth, LAC countries have a large proportion of youth, averaging 19 percent in 2005. ${ }^{7}$ Haiti is above average for LAC, with slightly over 20 percent of the population at age 15-24.

\footnotetext{
${ }^{7}$ US Census Bureau: http://www.census.gov/ipc/www/idbnew.html.
} 


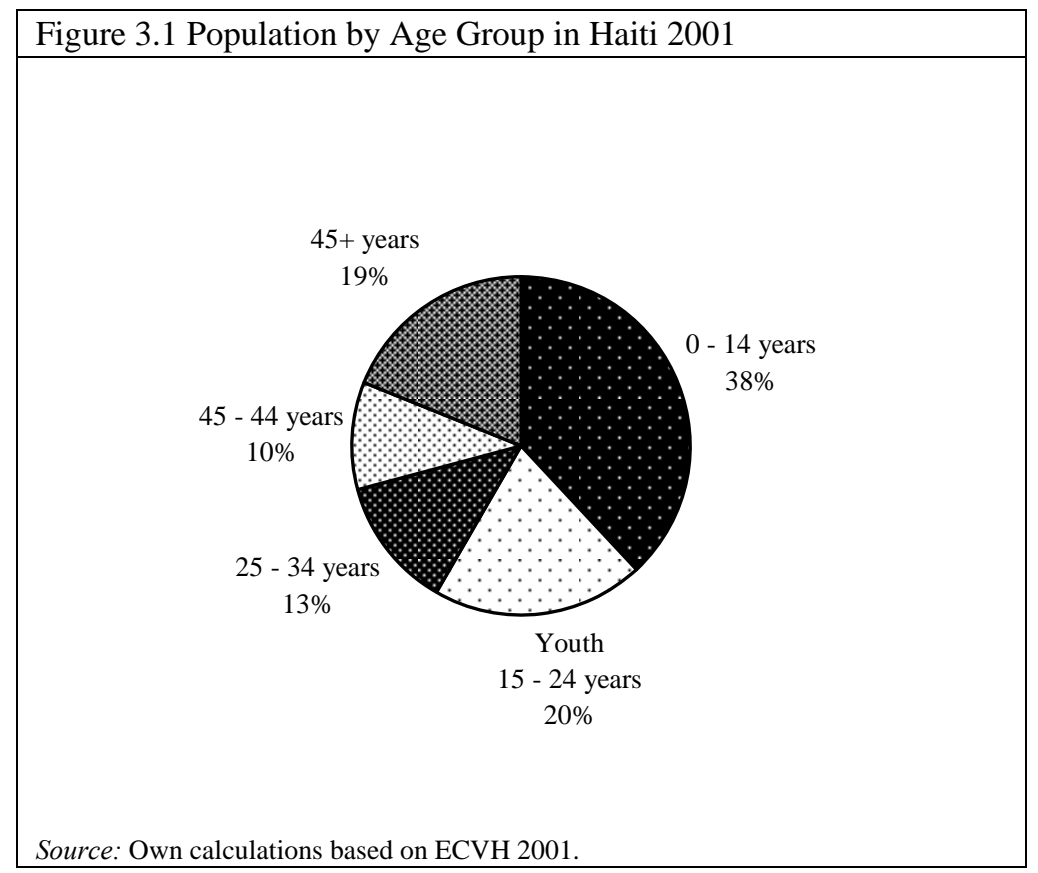

Twenty percent of the population is aged 15-24; this translates into 1.6 million Haitians out of the total population of nearly 8 million. As Table 3.1 shows, youth are not equally represented in all parts of Haiti. Less than 17 percent of the population are youth in the Center, Grand-Anse, and Southeast regions. The West, the most populous region including the capital Port-au-Prince, has more than 23 percent. In fact, the West region is home to more than 45 percent of Haiti's entire youth population. In contrast, the least populous regions, such as Northeast and Southeast, are home to only 3 and 4 percent, respectively, of Haiti's youth population.

\begin{tabular}{lrcrc}
\hline \multicolumn{5}{l}{ Table 3.1 Population Distribution in Haiti } \\
\hline & $\begin{array}{c}\text { Total } \\
\text { Population }\end{array}$ & $\begin{array}{c}\text { Youth aged } \\
\text { 15-24 (percent) }\end{array}$ & $\begin{array}{c}\text { Youth } \\
\text { Population }\end{array}$ & $\begin{array}{c}\text { Age 35-44 } \\
\text { (percent) }\end{array}$ \\
\hline Artibonite & $1,070,397$ & 20.3 & 217,291 & 10.7 \\
Center & 565,043 & 16.6 & 93,797 & 10.3 \\
Grand-Anse & 603,894 & 16.3 & 98,435 & 9.6 \\
North & 773,546 & 19.1 & 147,747 & 10.3 \\
Northeast & 300,493 & 18.4 & 55,291 & 9.3 \\
Northwest & 445,080 & 19.2 & 85,455 & 9.9 \\
West & $3,093,699$ & 23.4 & 723,926 & 11.3 \\
South & 627,311 & 18.1 & 113,543 & 8.3 \\
Southeast & 449,585 & 15.6 & 70,135 & 8.6 \\
\hline Haiti & $7,929,048$ & 20.1 & $1,593,739$ \\
\hline \multicolumn{5}{c}{ Note: Population from HLCS 2003b, percent based on calculations in ECVH 2001. } \\
\hline \multicolumn{5}{c}{. }
\end{tabular}
Source: Own calculations based on ECVH 2001. 
A comparison of the youth cohort to older cohorts shows that the former is by far the largest. The age group 35-44 years is about half the size of the youth cohort (Table 3.1). Because of the short life expectancy of only 52 years in Haiti and a high birth rate of 4.2 children per woman in $2003,{ }^{8}$ cohorts are quickly shrinking with increased age in absolute and relative size. Figure 3.2 shows that youth in fact are not the largest cohort. The cohorts of children are larger than youth, suggesting that youth may become an even larger group in the decade to come. ${ }^{9}$ Projections show that the pyramid-shaped demographics figure for Haiti, in contrast to other LAC countries such as Brazil, is not likely to change dramatically for at least the next two to three decades (Jiménez 2005). Because youth constitute a large proportion of the population it is clear than any plan for increased economic growth, decreasing poverty, improved health and education, and a generally stable and peaceful society needs to include youth.

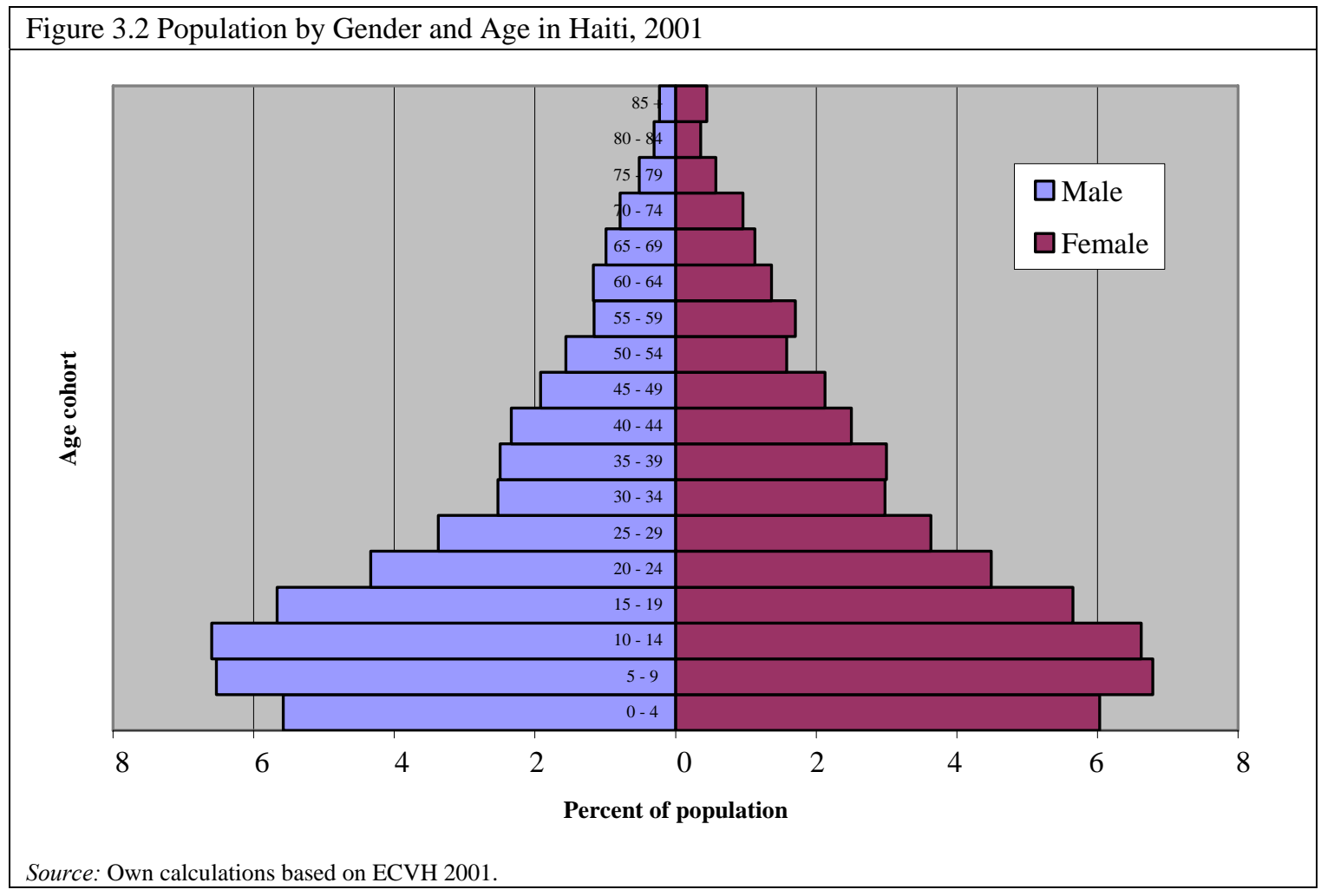

\section{Income Poverty}

Haiti is the poorest country in LAC. Nearly half of all households live in extreme poverty, and because poorer households tend to be larger on average, more than half of the population is extremely poor. Table 3.2 shows household income poverty incidence

\footnotetext{
${ }^{8}$ World Development Indicators.

${ }^{9}$ While Figure 3.2 shows a shrinking population at the very bottom of the pyramid, a 2003 census shows a more constant evolution with the younger cohorts as large as earlier cohorts (Jiménez 2005). This discrepancy may result from the ECVH's use of a master sample based on an earlier census.
} 
with a poverty line of US $\$ 1^{10}$ per day for the nine regions and Haiti as a whole. Because the West, where the capital is located, contains the lowest proportion of extremely poor households in Haiti (29 percent) and is also where nearly half of all youth live, concern for metropolitan (Port-au-Prince) youth could appear to be less than for those in the country as a whole (49 percent in extreme poverty). Nevertheless, metropolitan youth do not have better opportunities than those in other urban (outside Port-au-Prince, henceforth referred to as urban) and rural areas. For example, youth unemployment and crime rates are higher than average in the capital. With Port-au-Prince as a magnet, Haiti's degree of urbanization changed rapidly from less than 25 percent in 1982 to over 40 percent in 2003. As a result, migrants have been forced to change their lives dramatically and family structures have also changed (see Section 5). In general, poverty is seen as a very serious problem - two-thirds of youth have this opinion - with the largest proportion in the metropolitan area. This may be explained to some extent by the high income inequality, ${ }^{11}$ the crime and disorder that follow, and differences in family size and structure between poor and nonpoor households (see Section 5).

\begin{tabular}{lc}
\hline \multicolumn{2}{c}{ Table 3.2 Household Poverty Incidence 2001 } \\
\hline Artibonite & Extreme Poverty (percent) \\
Center & 58.6 \\
Grand-Anse & 55.6 \\
North & 60.8 \\
Northeast & 62.7 \\
Northwest & 80.3 \\
West & 65.0 \\
South & 28.9 \\
Southeast & 63.0 \\
\hline Haiti & 56.6 \\
\hline \multicolumn{2}{c}{48.9} \\
\hline
\end{tabular}

Extreme poverty is a serious risk factor for youth development. The macro environment in general provides insufficient opportunities for youth. The government's lack of means has led to malnutrition, degradation and lack of investment in infrastructure, and low quality and quantity of public education and health services. This situation leads to serious negative impacts on youth including low educational attainment, low social capital accumulation, poor health, and violent behavior (Moser and Bronkhorst 1999, Schneidman 1996). In addition, extreme poverty forces Haitians to discount the future heavily, engaging only in short-run engagements with immediate returns. ${ }^{12}$ Thus, besides having a direct impact on people's lives, alleviating poverty would also have secondary positive effects on livelihoods by allowing a change in focus to the medium and longer term.

\footnotetext{
${ }^{10}$ Including self-consumption and PPP adjusted.

${ }^{11}$ Gini coefficient of 0.66 for Haiti as a whole.

${ }^{12}$ This includes working in the informal sector, but also undertaking illegal activities.
} 
Frustration and desperation because of poverty may lead to aggressive behaviors such as crime and violence. Moreover, effects impact other risk factors such as school dropout and push out. As described above, targeting at-risk youth needs to be based not only on income poverty indicators, but also on a number of risk and protective factors which will be addressed in the following sections.

\section{Education and the Labor Market}

\section{Education and Drop out and Push out}

Illiteracy is widespread in Haiti but has been rapidly decreasing since the 1970s. In 1970, 78 percent of the population was illiterate, while in 2000 less than 40 percent was (UNDP 2002). This marked drop is explained by increasing years of education, stemming from a great concern by Haitians about education. The general level of trust in schools and in teachers' skills is great. This trust motivates most parents to send their children to school although public provision is scarce and quality is unregulated ${ }^{13}$ (Salmi 2000). As a result, school attendance rates for children and youth are relatively high. Most schools are private and 80 percent of students attend these. ${ }^{14}$ More than three out of four aged 6-14 attend school; however, at age 15-24 a transition naturally occurs from school into the labor market, which decreases school enrollment rates. Nevertheless, the decrease in school attendance is too rapid to provide secondary or tertiary education to a sufficient proportion of the youth. Table 4.1 reveals that nearly two out of three youth aged 15-22 abandon school altogether.

\begin{tabular}{lccc}
\hline \multicolumn{4}{l}{ Table 4.1: Proportion undertaking Education 2001} \\
\hline Age & Percent & Age & Percent \\
\hline $15-16$ & 76.6 & $15-19$ & 67.7 \\
$17-18$ & 65.3 & $20-24$ & 28.8 \\
\cline { 2 - 4 } $19-20$ & 44.8 & $15-24$ & 50.7 \\
\cline { 2 - 4 } $21-22$ & 29.0 & $25-34$ & 4.2 \\
$23-24$ & 22.6 & $35-44$ & 0.1 \\
\hline \multicolumn{4}{c}{ Source: Own calculations based on ECVH 2001. }
\end{tabular}

In terms of educational attainment youth are doing better than older generations. The maximum level of education attained is higher for youth than their older peers even though more than 50 percent of youth are still enrolled. According to Table 4.2, 46.6 percent of youth had completed primary education in 2001. This is 54 and 64 percent more than the cohorts aged 25-34 and 35-44, respectively. A slightly larger proportion of youth than of the age group 25-34 has completed secondary education, while these

\footnotetext{
${ }^{13}$ In a representative test of 1200 public and private schools in 1996, one-third of teachers at the primary level did not know how to rank words alphabetically (Salmi 2000).

${ }^{14}$ While 80 percent of the limited public expenditures go to Port-au-Prince, spending on education represents only two percent of GDP, less than half of that of other developing countries (World Bank 2005b).
} 
proportions are nearly the double that for the age group 35-44. In LAC nearly half of 20year-old youth have not completed secondary education and as many as three out of four in rural areas have not completed this level (La Cava et al. 2004). In Haiti figures are worse than the LAC region's average because more than half of 20-year-olds do not have secondary education and only one out of three has completed it in rural areas. As Verner (2005) shows, education has a large significantly positive wage return in Haiti. Moreover, education is a protective factor because it preempts most negative outcomes and leads to postponed age of starting families, better health, fewer children, prioritization of children's education, better preparation for the labor market, and therefore better jobs and higher income. Yet, as Jiménez (2005) states, 85 percent of slum dwellers' children in Rio de Janeiro had higher education than their parents, but just 59 percent had better jobs. Such frustrated expectations may lead to anger and violence. Therefore, it is also important to create opportunities for those who have completed their education.

\begin{tabular}{lcccc}
\hline \multicolumn{5}{l}{ Table 4.2: Level of Completed Education 2001 (percent) } \\
\hline Age & No education & Primary & Secondary & Tertiary \\
\hline $15-19$ & 13.4 & 55.8 & 30.7 & NA \\
$20-24$ & 17.6 & 34.7 & 47.0 & 0.6 \\
\hline $15-24$ & 15.2 & 46.6 & 37.9 & 0.3 \\
\hline $25-34$ & 28.7 & 30.3 & 37.4 & 3.6 \\
$35-44$ & 48.1 & 28.5 & 20.8 & 2.5 \\
\hline
\end{tabular}

Source: Own calculations based on ECVH 2001.

A series of factors, such as high costs, housework, or marriage, results in youth not attending school. Some youth never enroll in school, some drop out or are pushed out, and some leave after completing their education. In connection to the positive relation between schooling and general performance in life, it is of interest to examine the characteristics of the group not attending school. This helps to identify factors that could increase incentives and possibilities for an increased education level in Haiti. Table 4.3 shows that the main reason for youth not attending school is that the cost of schooling is too high. ${ }^{15}$ More than nine out of ten parents expect their child to graduate. However, for children who do not graduate, two out of three parents give high education costs as the main reason for not expecting their children to complete their education. In addition, illness, repeated failure, marriage, restrictions for girls, family disintegration, and work in or outside the household are important factors for not attending school (see Table 4.3), as discussed below.

\footnotetext{
${ }^{15}$ In 1980 the direct cost of schooling represented on average around 12 percent of per capita income. In comparison average expenditures in other low-income countries were 3 to 4 percent of household income (Salmi 2000).
} 


\begin{tabular}{lc}
\hline Table 4.3: Reasons for Youth not to Attend School, 2001 (percent) \\
\hline Too costly & 38.8 \\
Not interested in school & 10.2 \\
Illness & 4.5 \\
Repeated failure & 4.2 \\
Left school for marriage & 3.0 \\
Family does not allow girl & 2.5 \\
Family disintegration & 2.4 \\
Housework & 1.9 \\
Work to support family & 1.3 \\
Other reason & 31.2 \\
\hline \multicolumn{2}{c}{ Source: Own calculations based on ECVH 2001. }
\end{tabular}

Source: Own calculations based on ECVH 2001.

Besides the self-reported reasons for not attending school there is generally a strong connection between parents' level of education and that of their children. This is the case as more educated parents tend to have more information, know the educational environment and what it requires, motivate their children to learn, and have better connections or sometimes better abilities. Moreover, there is a connection because of the correlation between parents' education and wealth, i.e., they can afford schooling. The situation in Haiti confirms this hypothesis. Figure 4.1 shows the proportion of uneducated household heads in relation to youth enrolled in school or not. Clearly the heads of household ${ }^{16}$ of youth who do not attend school are less educated than the heads of those who attend. Compared to household heads with youth in the household attending school, 23 percent more of household heads with youth in the household out of school have no primary education. ${ }^{17}$ It is also clear from Figure 4.1 that education of household heads is not only decisive for youth undertaking education or not, but also for how long time youth spend in school, and thus the level of education they achieve. Those who stay longer in the school system come from households with higher educated heads.

A multivariate probit model is used to examine school dropout in further detail. The probit model measures the marginal impact of a set of characteristics on the probability of school dropout and push out (henceforth dropout). ${ }^{18}$ Data only allow a cross-section analysis, thus not taking dynamics into account such as changes in the schooling system over time. This model's results should be seen as correlates since causality is not established. The analysis will help target specifically vulnerable groups of youth. Regressing dropout on a set of variables gives the findings presented in Table 4.4.

\footnotetext{
${ }^{16}$ Because many children live away from their biological parents (see Section 5) the household head is more likely to have a parental role. Because of this and matters of consistency in the data, household heads are used instead of parents. The results are conditioned on the household head not being a youth.

${ }^{17}$ On average for each year and group of youth.

${ }^{18}$ School dropout and push out are not directly observed in the sample. Thus, youth out of school is used as a proxy for dropout and push out.
} 


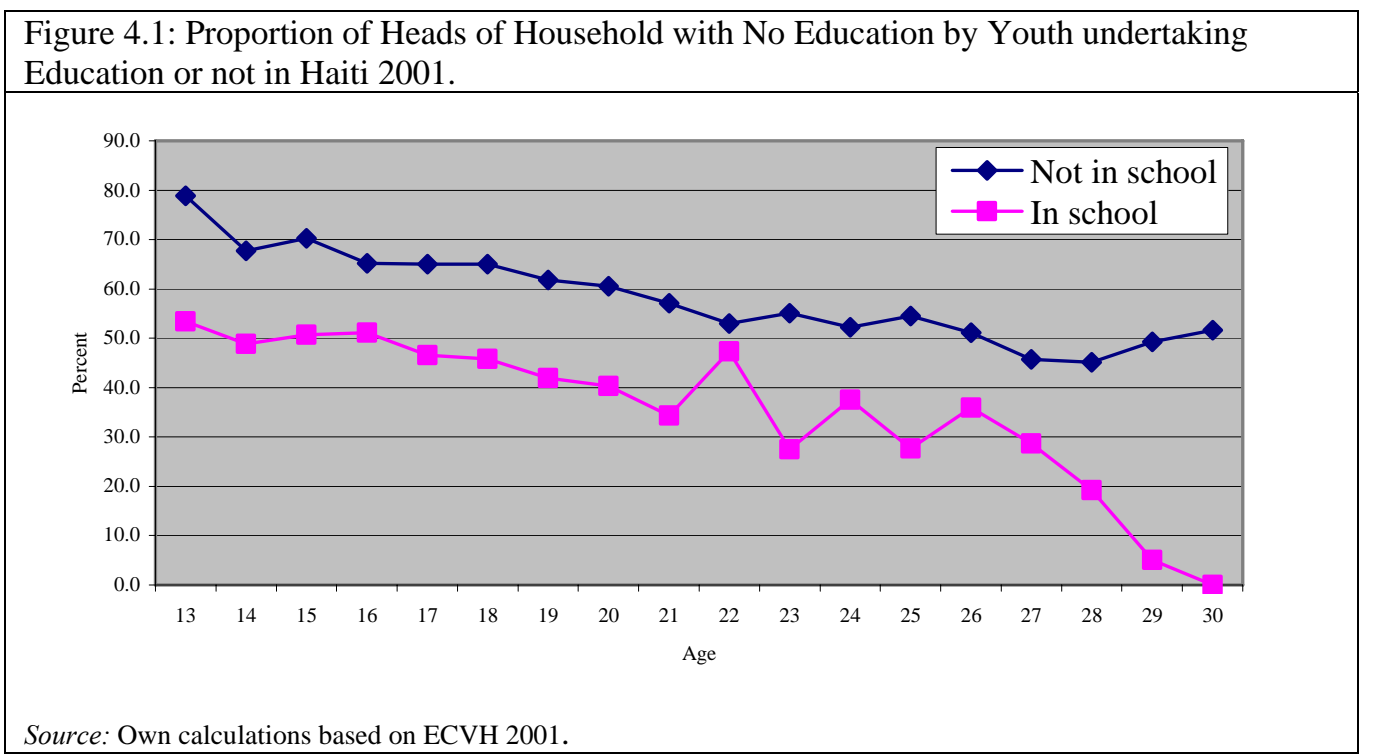

The older the youth is the more likely (but decreasingly so) he or she is to leave school. Graduating from primary or secondary school has a large negative impact on the probability of leaving the educational system compared to not having completed the primary level, i.e., completing a level of education makes the youth less likely to drop out ceteris paribus. Household size is negatively correlated with school dropout. That is, the larger the household size the lower is the likelihood of youth not attending school. This is consistent with the fact that some families have domestic labor in order to enroll their own children in school. Yet the result is surprising because on average poor families tend to be larger than nonpoor families. But it does confirm our field work which clearly showed that poor households value education very highly and spend all their savings on educating their children. However, youth in a newly started family must provide for themselves by working, and when the family grows the oldest children must support the household. Having their basic needs taken care of by older siblings may allow one or more of the siblings to attend school as a family investment. Moreover, it is common to send children and youth to other households for the purpose of education. The household of origin may send money for schooling, hoping that the new household will send the child to school in return for work as a domestic servant or perhaps a combination of the two (Sommerfelt 2003).

In Haiti, religious practice is correlated with dropping out of school. Compared to Baptists and other religiously affiliated persons, Catholics and Voodooists are more likely to not attend school. One explanation may be that the number of Protestant missions has increased rapidly in recent years in Haiti. The Baptists ${ }^{19}$ have a network of private schools around the country and tend to strongly emphasize education; as findings indicate, the efforts seem to be paying off in terms of reduced dropout rates relative to other religiously affiliated youth.

\footnotetext{
${ }^{19}$ Baptism is the main Protestant affiliation in Haiti.
} 
Youth in the metropolitan and rural area are more likely than youth in other urban areas to leave school. In rural areas this may be explained by poverty, distance to schools, and need for supplying farm labor, while in the metropolitan area security (discussed in Section 6) and increased labor market opportunities are likely explanations for this finding.

Females are statistically significantly more likely than their male peers to drop out of school. Possible explanations are that female youth may have to help take care of their siblings, perform housework, etc. (see Section 5). Likewise, marriage has an even larger positive impact on the probability of dropping out of school. Marriage may mean having children, which negatively affect females' school attendance, and for males marriage may mean increased responsibility and a new position as breadwinner, leaving little time or money for attending school.

\begin{tabular}{|c|c|c|c|}
\hline Dropout & Coefficient & Std. Err. ${ }^{21}$ & $\mathrm{t}$ \\
\hline Age & 0.664 & 0.127 & 5.21 \\
\hline Age squared & -0.011 & 0.003 & -3.22 \\
\hline Female* & 0.142 & 0.044 & 3.20 \\
\hline Family size & -0.028 & 0.008 & -3.46 \\
\hline Metropolitan* & 0.192 & 0.069 & 2.76 \\
\hline Rural* & 0.090 & 0.051 & 1.77 \\
\hline Primary education* & -1.690 & 0.090 & -18.77 \\
\hline Secondary education* & -2.487 & 0.100 & -24.79 \\
\hline Married* & 1.285 & 0.112 & 11.47 \\
\hline Head-primary education* & -0.153 & 0.051 & -2.98 \\
\hline Head-secondary education* & -0.208 & 0.068 & -3.07 \\
\hline Head-tertiary education* & -0.410 & 0.165 & -2.48 \\
\hline Catholic* & 0.171 & 0.058 & 2.95 \\
\hline Voodoo* & 0.276 & 0.161 & 1.72 \\
\hline Other religions* & -0.083 & 0.067 & -1.24 \\
\hline Constant & -7.024 & 1.213 & -5.79 \\
\hline
\end{tabular}

Source: Own calculations based on ECVH 2001.

Parents' completed level of education serves as a protective factor for children and youth attending school. The education of the household head is used as an indicator for parents' education (see Section 5). Table 4.4 shows a statistically significant negative effect of the heads' level of completed education on the probability of their children not being in school. ${ }^{22}$ The more education attained by the head of household, the less likely it

\footnotetext{
${ }^{20}$ Family size squared and migration status were included as explanatory variables in early regressions, but came out statistically insignificantly different from zero.

${ }^{21}$ Standard errors are adjusted for the clustering process in the sample procedure from the EVCH survey.

${ }^{22}$ This is in line with other studies (e.g., Saraví 2002).
} 
is that the household's young members will drop out of school in Haiti. Moreover, the impact of education increases sharply with the level completed. Clearly, guidance, encouragement, and expectations are important for keeping youth in school. ${ }^{23}$

Significant proportions of youth work at an early stage in life and thus take on a burden, increasing the risk of school dropout rather than completing their education. Besides increased school dropout rates, premature entry to the labor market, such as youth working while in school and in specific child labor, is also generally associated with lower academic performance. Of the age cohort 15-19, 13 percent are working and in school, and 26 percent of the cohort 20-24 years are dually engaged. School dropout can result from a number of factors. Besides the observed traits discussed already, youth who drop out of school generally have different unobserved traits than those graduating: lower motivation, ability or expectations of return, comparative advantage of jobs for nongraduates, higher value of leisure, and lower consumption value of attending school (Eckstein and Wolpin 1999). It is therefore important to increase possibilities and incentives for potential dropouts to continue schooling.

Having measured the effects of characteristics on the probability of not attending school it is interesting to consider the occupation of this group. Similar to the above analysis the effects on the probability of being unemployed or inactive are investigated below in order to further disaggregate youth and identify those at risk.

\section{The Labor Market}

Penetrating the labor market and getting a job in Haiti are very difficult for youth; getting a good job is even harder. Practically everyone in Haiti finds unemployment to be a serious problem and more than two out of three Haitian youth find it to be a very serious problem. Figure 4.2 shows main activity by age. Eight out of ten youth go to school at age 13, around one out of two at age 19, and less than one out of five at age 24 . Those who leave school enter the labor market or become inactive because of illness, teen pregnancy, work in the household, engagement in illegal activities, or other reasons. The proportion of unemployed and inactive is between an astonishing 45 and 55 percent for the age group 20-30. On average 26 percent of all youth out of school are unemployed ${ }^{24}$ and as many as 44 percent are inactive (Table 4.5). For comparison, Table 4.5 also shows the activity for the age group 35-44 where the proportion of those inactive is just 20 percent; less than half of that for youth. Table 4.6 shows the unemployment rates for different age groups participating in the labor market: 40.6 percent of male youth and 54.8 percent of female youth are unemployed. These unemployment rates are the highest in LAC and high even compared to the second highest incidence available for

\footnotetext{
${ }^{23}$ These results are not likely to capture income effects because including income quintiles for the household only gave a negligible negative effect for the richest 20 percent.

${ }^{24}$ Notice this is not the unemployment rate because those inactive are included (Table 4.6 shows unemployment rates).
} 
LAC in $1999,{ }^{25}$ which are for Jamaica with 19.1 and 31.8 percent, respectively, of male and female youth being unemployed. Clearly unemployment is a problem specific to youth because the unemployment rate drops markedly to 34.5 and 20.2 for the age groups 25-34 and 35-44 years, respectively. Thus, youth unemployment appears to follow the pattern from other LAC countries where the average rate is far higher than the adult unemployment rate ( 8 and 16.6 percent, respectively, on average in LAC), but the level is far higher in Haiti. Moreover, unemployment is higher in Port-au-Prince, where a large proportion of youth reside, than outside the metropolitan area. The large group of inactive youth should not be forgotten, but in Haiti few can afford to be truly inactive and many girls have hard, unpaid work in a household, and boys may be engaged in illegal activities, which in the household data are considered as inactivity. Under all circumstances, the Haitian labor market is not easily accessible and leaving school does not simply happen because of job offers, but to a large extent because of costs or need for support in the household. ${ }^{26}$ Moreover, in Port-au-Prince some youth may be able to afford inactivity or unemployment because of remittances from relatives abroad.

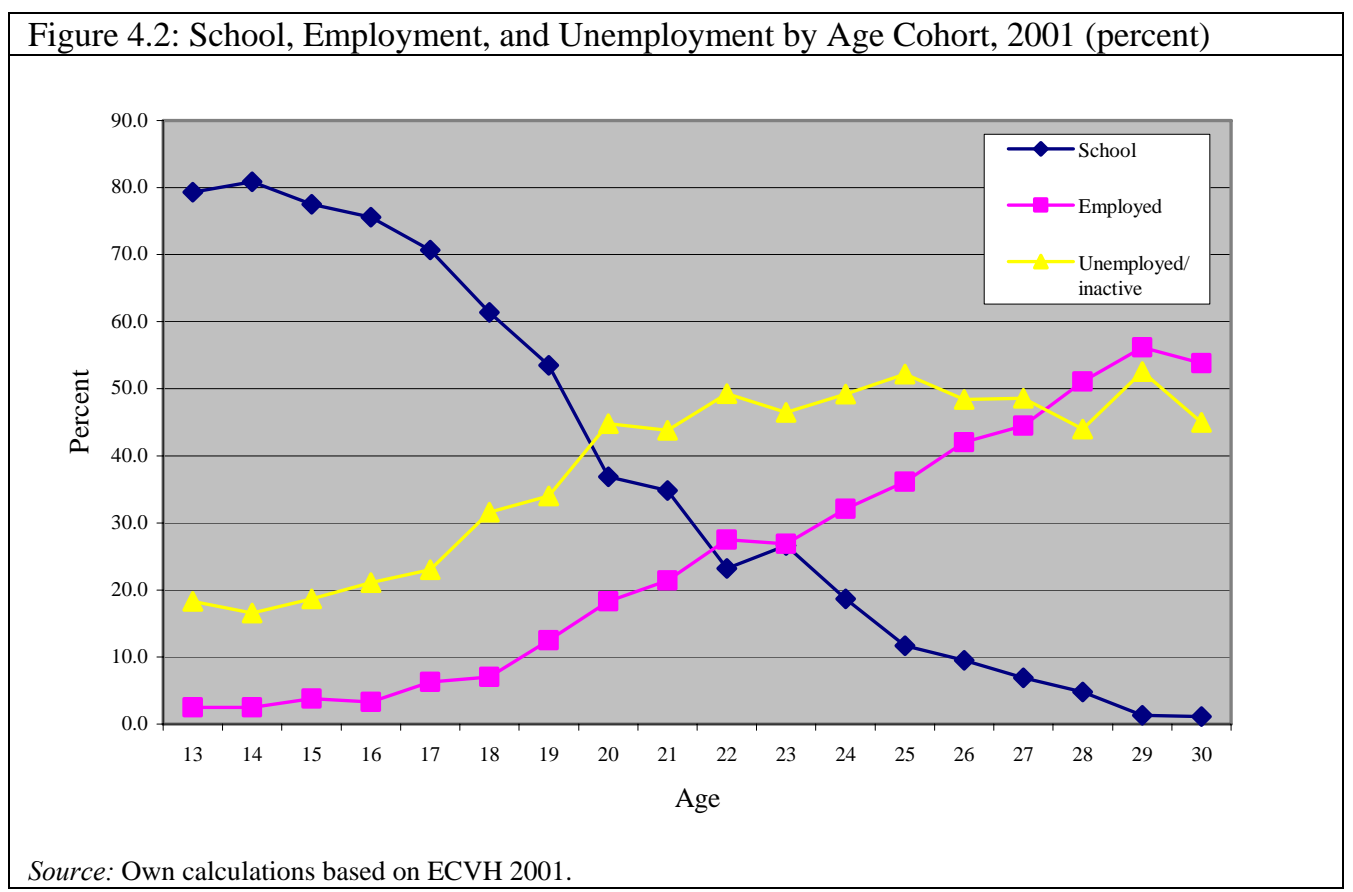

\footnotetext{
${ }^{25}$ Of countries with available data in 2003 (i.e., not including Haiti), St. Lucia had the highest rate of youth unemployment between 1996 and 1998 with 30.6 percent being unemployed, according to the World Bank (2003).

${ }^{26}$ For example, one person often needs to stay in the household to claim it because many do not have a deed.
} 


\begin{tabular}{lccc}
\hline $\begin{array}{l}\text { Table 4.5: Activity when Not Attending School, } 2001 \\
\text { (percent) }\end{array}$ & \multicolumn{3}{l}{} \\
\hline Age & Employed & Unemployed $^{27}$ & Inactive \\
\hline $15-19$ & 20.1 & 24.0 & 55.9 \\
$20-24$ & 34.6 & 27.8 & 37.6 \\
\hline $15-24$ & 29.3 & 26.4 & 44.3 \\
\hline $25-34$ & 53.4 & 23.2 & 23.4 \\
$35-44$ & 67.2 & 12.6 & 20.2 \\
\hline
\end{tabular}

Source: Own calculations based on ECVH 2001.

\begin{tabular}{lccc}
\hline \multicolumn{4}{l}{ Table 4.6: Unemployment Rates, 2001 (percent) } \\
\hline Age & Male & Female & Total \\
\hline $15-19$ & 46.4 & 62.9 & 54.3 \\
$20-24$ & 38.3 & 51.4 & 44.5 \\
\hline $15-24$ & 40.6 & 54.8 & 47.4 \\
\hline $25-34$ & 24.1 & 34.5 & 29.1 \\
$35-44$ & 11.4 & 20.2 & 15.6 \\
\hline
\end{tabular}

Unemployment and premature entry to the labor market have a number of negative effects such as lower self-esteem, depreciation of skills, as well as negative effects on earnings potential, lower schooling and human capital stock, and lack of role models for children and youth. In addition, lost tax revenues for the state, reduced household income, and crime and violence (see Section 6) may result from unemployment.

A larger proportion of male youth attend school than females at the same age. Even though this appears to contrast with men as breadwinners it is explained by many girls working in their household, some of whom are not allowed to attend school. With a female unemployment rate 35 percent higher than the male unemployment rate, males are unemployed to a much lesser extent than females (Table 4.6). However, getting a job in Haiti is far from a clear path to fortune or even to a decent standard of living. The quality of jobs is generally low because wages are low and work is often extremely tiring. In rural areas the abundant supply of labor outside harvest season reduces salaries and wages. It is clearly not enough to simply create jobs; it is also important to improve the conditions for those who work.

In Haiti, only 29.3 percent of youth who do not attend school are employed (Table 4.5). For youth who find employment, Figure 4.3 shows the distribution of workers by sector. Two main sectors absorb youth: agriculture and service. Agriculture is by far the main sector for the age cohort 15-19 and absorbs a decreasing proportion of the labor force with increasing age. Public sector and other formal sector jobs are the hardest to obtain because they require education and connections and are therefore practically inaccessible for the majority of youth, especially for those from poor households.

\footnotetext{
${ }^{27}$ This is not the unemployment rate because those inactive are included (Table 4.6 shows unemployment rates).
} 


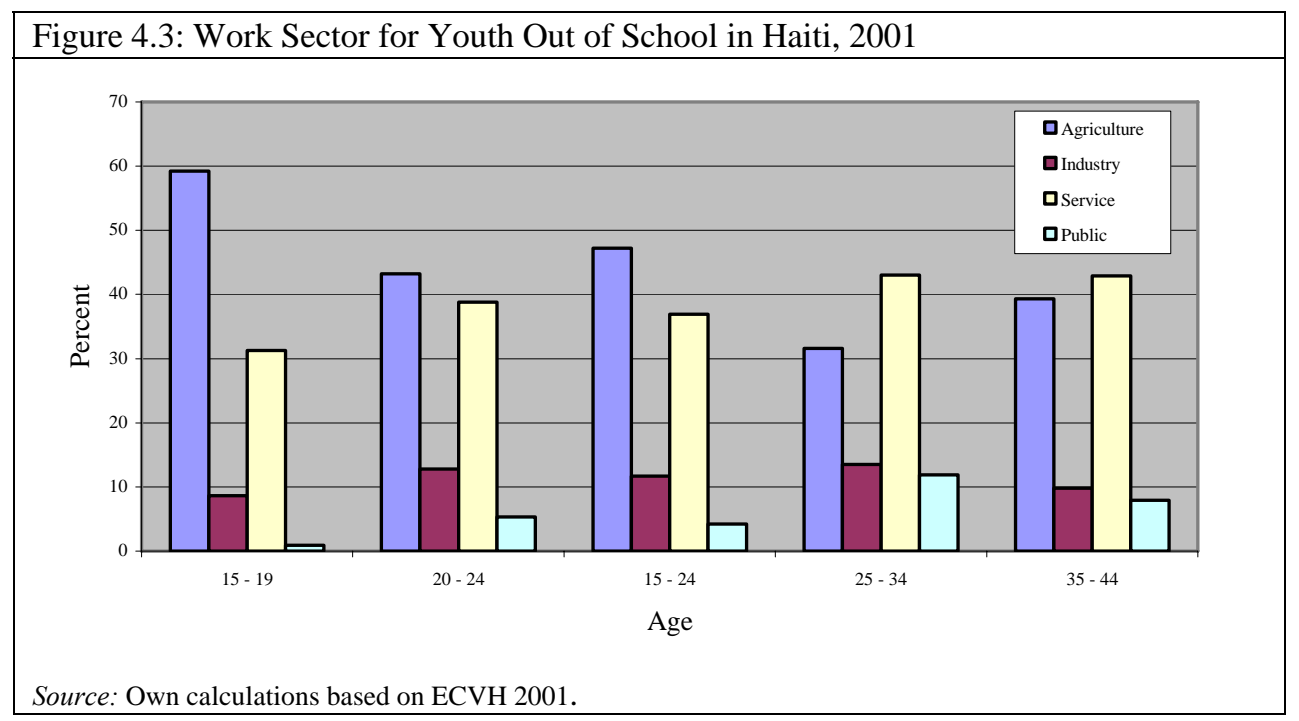

Table 4.7 disaggregates work sectors by gender. The statistics reveal that the labor market in Haiti is dual: one for men and one for women. While 62 percent of employed male youth work in agriculture only 26 percent of employed female youth do. In contrast, 65 percent of employed female youth work in the service sector, but only 17 percent of employed male youth do. This pattern is unchanged over increasing age.

\begin{tabular}{l|cccc|cccc}
\hline \multicolumn{1}{c}{ Table 4.7: Work Sector by Gender, 2001 (percent) } \\
\hline \multicolumn{7}{c}{ Male } \\
\hline Age & Agriculture & Industry & Service & Public & Agriculture & Industry & Service & Public \\
\hline $15-19$ & 76.8 & 11.7 & 11.5 & 0.0 & 32.1 & 3.7 & 61.8 & 2.4 \\
$20-24$ & 57.0 & 16.8 & 19.3 & 6.9 & 23.7 & 7.1 & 66.3 & 3.0 \\
\hline $15-24$ & 62.1 & 15.5 & 17.3 & 5.1 & 25.7 & 6.3 & 65.2 & 2.8 \\
\hline $25-34$ & 43.3 & 19.3 & 23.3 & 14.1 & 16.8 & 6.1 & 68.1 & 9.1 \\
$35-44$ & 54.2 & 13.7 & 24.4 & 7.7 & 21.4 & 5.2 & 65.3 & 8.1 \\
\hline \multicolumn{8}{c}{ Source: Own calculations based on ECVH 2001. }
\end{tabular}

To take the labor market analysis one step further, a probit model (see above) is estimated. The marginal impact of characteristics is used to estimate the probability of being unemployed or inactive versus being employed. This regression and the analysis above (Table 4.4) make it possible to identify characteristics of vulnerable youth. Table 4.8 shows findings from the probit regression on unemployment/inactivity (henceforth unemployment).

For youth who are not attending school, age-as an indicator of experience and search time-is negatively associated with the probability of being unemployed. This indicates that as the young people become older they are less likely to be unemployed. In contrast to the education level of youth themselves, the education level of the household 
head has a statistically significant negative impact on the probability of being unemployed; this shows that support, expectations, and connections from older family members not only contribute to youth staying in school, but also to their finding employment when they leave school. ${ }^{28}$

In the metropolitan area, where a large proportion of youth reside, youth are more likely than their peers in rural and urban areas to be unemployed. While some of this effect may be explained by the presence of richer families that are able to afford the idleness of their children, the main finding is that the capital area is not providing enough opportunities for youth, e.g., because of security issues (see Section 6) and lack of investments. In this regard, it is also surprising to see that youth with primary and secondary education are more likely to be unemployed than those with no education. As mentioned above, an explanation for this may be that some of those with secondary education are from richer families and can therefore afford longer job search time (or simply inactivity) than their uneducated or poorer peers. Another reason for extended search time for higher educated youth could be the connection between education and reservation wage: when the level of education increases, the minimum wage for a worker to accept a job increases, and thus the average waiting time for an acceptable job offer increases (Mortensen 1986). Furthermore, given the labor market situation in Haiti with consistently high youth unemployment and underemployment and thus many long-term unemployed and underemployed, it may be the case that job mobility is higher among the least educated youth and that higher educated youth cannot find a job because employers tend to keep their educated workers longer (efficiency wage hypothesis-Saygili 1998, Katz 1986). It may also be that uneducated youth drop out because of job offers and because they have traits that give them an advantage in the first years in the labor market, while the opposite is the case for older workers. A third explanation relates to the experience from other large cities in Latin America such as Rio de Janeiro where educated youth do not benefit as much as expected from education (Section 3). In Haiti, the result may also stem from the poor quality of education. More research on the connection between education and unemployment is needed to fully understand why education increases the likelihood of unemployment ceteris paribus.

Females are more likely to be unemployed than their male peers, keeping other things constant. Considering that they are also more likely to leave school earlier than male youth, women are clearly in a vulnerable position. Gender issues need to be on the agenda for a development plan in Haiti to increase equality and well-being. Considering the difference between young males and females in the proportion of those attending school, the high unemployment rate for females, the duality of the labor market, and the higher probability of dropping out and becoming unemployed or inactive, a program needs to be designed that strongly emphasizes women. In order to pinpoint the optimal strategy for such a program, more research on gender issues is needed.

Religious affiliation also affects the probability of being unemployed, but while Catholics and Voodooists are more likely than their peers to leave school they are less

\footnotetext{
${ }^{28}$ Saraví (2002) also finds that social capital in form of family characteristics is strongly associated with opportunities as well as the quality of jobs offered in Argentina.
} 
likely to be unemployed. Thus, a reason for leaving school at an early age for this group may be a greater availability of jobs. However, the result may stem from the fact that because Baptists are more likely to stay in school, dropout Baptists are a group with lower mean characteristics than their peer group of dropouts. ${ }^{29}$

Marriage appears to force youth out of school and into employment. Tables 4.4 and 4.8 show that marriage is statistically significantly positively related to the probability of being out of school and is negatively related to being unemployed. Because the quality of jobs is not accounted for in the model, the positive correlation may be that married youth are indirectly forced to accept any job available to provide for the spouse, etc. On the other hand, economics of the family generally suggest that people who are married have better traits than their peers and married individuals would therefore be more likely to find (good) jobs.

\begin{tabular}{lccc}
\hline \multicolumn{4}{c}{ Table 4.8: Probability of Youth being Unemployed or Inactive, $2001^{30}$} \\
\hline \multicolumn{1}{c}{ Unemployed/inactive } & Coefficient & Std. Err. & $\mathrm{t}$ \\
\hline Age & -0.377 & 0.168 & -2.24 \\
Age squared & 0.007 & 0.004 & 1.70 \\
Female* & 0.576 & 0.061 & 9.39 \\
Metropolitan* & 0.280 & 0.108 & 2.60 \\
Rural* & -0.023 & 0.071 & -0.33 \\
Primary education* & 0.112 & 0.066 & 1.69 \\
Secondary education* & 0.441 & 0.086 & 5.13 \\
Tertiary education* & -0.113 & 0.380 & -0.30 \\
Migrated* & -0.276 & 0.088 & -3.12 \\
Married* & -0.313 & 0.081 & -3.86 \\
Head-primary education* & -0.134 & 0.070 & -1.92 \\
Head-secondary education* & -0.090 & 0.102 & -0.88 \\
Head-tertiary education* & -0.017 & 0.285 & -0.06 \\
Catholic* & -0.204 & 0.084 & -2.41 \\
Voodoo* & -0.372 & 0.195 & -1.91 \\
Other religions* & -0.310 & 0.097 & -3.18 \\
Constant & 5.124 & 1.659 & 3.09 \\
\hline Note: No. observations: 2859 . ${ }^{*}$ is a discrete dummy variable; $\mathrm{t}$ is the test of the \\
underlying coefficient being equal to 0. Household heads excluded. Variables left out: \\
Urban, no education, head no education, Baptist. \\
\hline \multicolumn{4}{r}{ Source: Own calculations based on ECVH 2001. } \\
\hline
\end{tabular}

Finally, although migration was not found to have an impact on the probability of dropping out of school, it does have a significantly negative impact on the probability of being unemployed. That is, migrants are more likely to be employed. This supports the theory that Haitian migrants are positively self-selected, as described below.

\footnotetext{
${ }^{29}$ Unobserved heterogeneity (Justesen 2004, Heckman and Singer 1984).

${ }^{30}$ Family size and family size squared came out statistically and insignificantly different from zero.
} 


\section{Migration}

Migration is a coping mechanism for youth and generally for the population, in response to unemployment, poverty, and lack of opportunities. In Haiti, more than one out of five persons aged 15 or older were not born in the same region as that of their current residence. Table 4.9 shows that in the most populous region, West, 36.7 percent of the population was born elsewhere in Haiti. This shows that the lives of Haitian youth are heavily affected by migration and the capital city is in most cases the destination for domestic migrants.

\begin{tabular}{lcc}
\hline \multicolumn{3}{c}{ Table 4.9: Domestic Migration 2001 (percent) } \\
\hline Artibonite & Migrated & Not migrated \\
Center & 7.6 & 92.4 \\
Grand-Anse & 15.3 & 84.7 \\
North & 11.5 & 88.5 \\
Northeast & 4.9 & 95.1 \\
Northwest & 23.6 & 76.4 \\
West & 1.9 & 98.1 \\
South & 36.7 & 63.3 \\
Southeast & 11.2 & 88.8 \\
\hline Total & 8.3 & 91.7 \\
\hline \multicolumn{2}{c}{ Source: Own calculations based on ECVH 2001. }
\end{tabular}

Migrants in Haiti are mainly economic migrants, whom Chiswick (1999) describes as: "more able, ambitious, aggressive, entrepreneurial, or otherwise more favorably selected than similar individuals who remain in their place of origin,” i.e., they are positively self-selected. This hypothesis is supported by Figure 4.4, which shows higher average years of schooling among migrants aged 15 and older who left a specific region, compared to those who stayed behind. ${ }^{31}$ Only the few who left the metropolitan area (which lies in West) are less educated than their peers. Yet their level of education is still higher than the average of other regions, giving them a competitive advantage by migrating. On average migrants have nearly three more years of completed education than nonmigrants.

\footnotetext{
${ }^{31}$ Data did not allow an examination of age at the time of migration so it was not possible to calculate the proportion of youth migrating.
} 


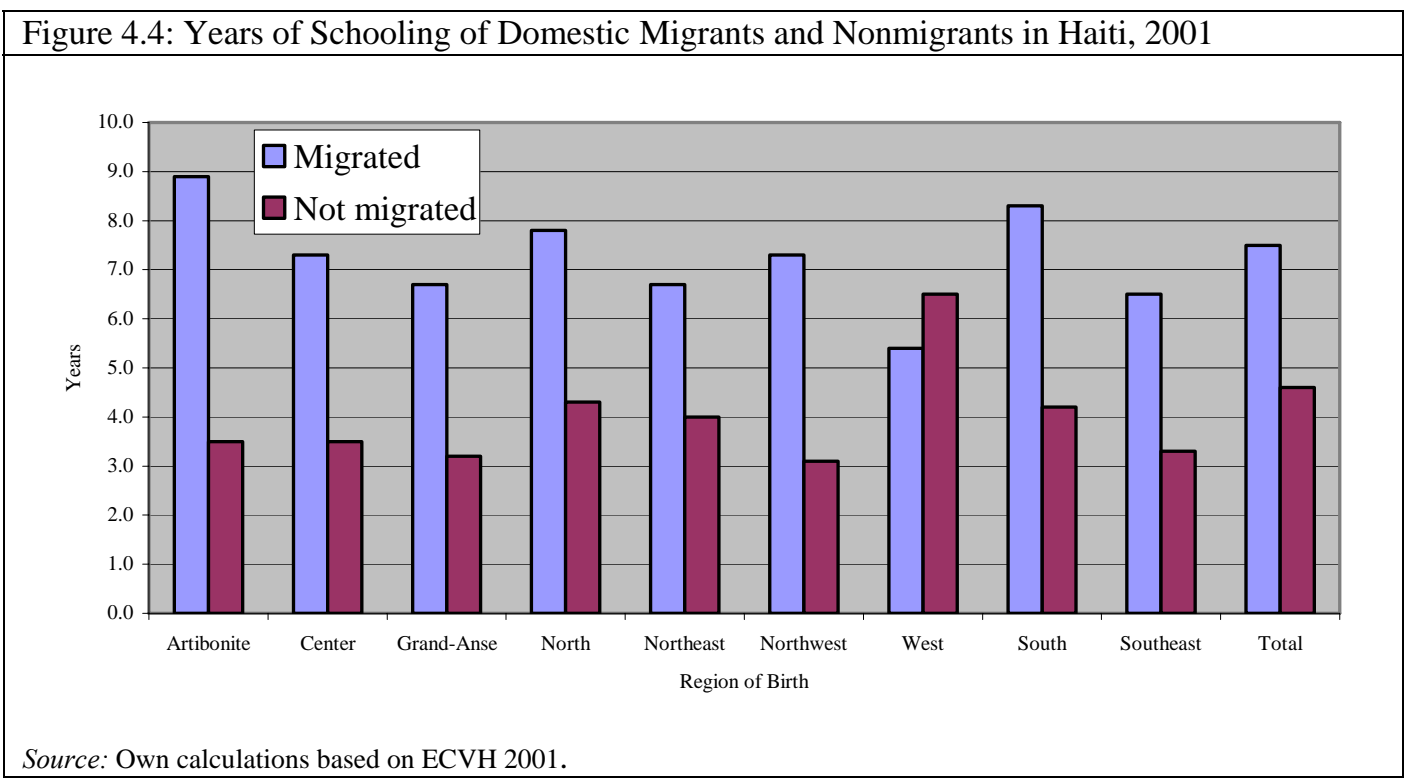

A variety of factors contribute to explain migration because not all migration is based on direct self-selection. To some surprise the majority of domestic migrants are women. The main reason for many women to migrate is that they follow their families (Table 4.10). However, positive assortative mating, ${ }^{32}$ as described by Becker (1973), would mean that the spouse of a self-selected migrant also has better traits than his or her peers. In addition, the fact that some traits are hereditary means that youth who follow their families are likely to be positively selected. On the other hand, the insecurity and changes that follow migration may stress youth and thereby represent a risk factor. More research on migration is needed to reveal its implications for migrating youth.

Table 4.10 reveals that education is an important factor for migration. This explains to some extent why urbanization is taking place and the majority of migrants move to Port-au-Prince, and also why youth and adults living in the capital have more education on average than those in other regions.

\begin{tabular}{lc}
\hline \multicolumn{2}{l}{ Table 4.10: Reason for Migration, } \\
\multicolumn{2}{l}{ Youth and Adults, 2001 (percent) } \\
\hline Followed family & 36.5 \\
Educational reasons & 13.0 \\
Personal reasons & 11.7 \\
Lack of work & 9.4 \\
Other (including work) & 29.4 \\
\hline \multicolumn{2}{c}{ Source: Own calculations based on ECVH 2001. }
\end{tabular}

\footnotetext{
${ }^{32}$ Mating of similar people "—positive assortative mating —is extremely common, whether measured by intelligence, height, skin color, age, education, family background, or religion...” (Becker 1973).
} 
Positive self-selection implies that migration generally tends to improve the financial situation of the migrant's household. ${ }^{33}$ The results in Table 4.8 show that youth who migrate are less likely to be unemployed or inactive than those who remain in their region of origin, controlling for attained education. In Haiti nearly all domestic migration has been from rural areas to the metropolitan area. Some migrants leave Haiti; based on flows of remittances there are indications that the highest educated Haitians from the richest households go to the USA or Canada, while less educated emigrants go across the border to the Dominican Republic. Going to the USA or Canada to study or work is a unique opportunity for youth, but few can afford it and have the necessary connections. The situation for Haitian emigrants in the Dominican Republic is a different matter because wages are low and jobs are often precarious (World Bank 2005f).

Although remittances are an important part of income for many families, emigration also leads to lack of qualified workers or brain drain in Haiti. Very few return migrants are observed in the household survey. For youth, the lack of parental role models (particularly fathers) these emigrants represent leaves an even greater gap. Migration may lead to stressful situations for children and youth if they are left behind with only one parent or with another family member or friends. Thus, migration of parents increases the risk of neglect of small children and youth. The following section will look deeper into the family structure.

\section{Family and Health Issues}

\section{Family and Gender}

The family is both the strongest protective factor and the strongest risk factor. Families in Haiti are relatively large, as already indicated by a fertility rate of 4.2 children per woman in 2003. Poor and extremely poor households are on average larger than nonpoor households and, as Table 5.1 shows, poor metropolitan households tend to contain more youth on average than other households. This shows that youth are overrepresented in Port-au-Prince because on average poor rural households tend to be larger (Table 5.2).

\begin{tabular}{lcccc}
\hline \multicolumn{4}{l}{ Table 5.1: Average Number of Youth per Household in Haiti, 2001 } \\
\hline Income (per capita) & Metropolitan & Urban & Rural & Haiti \\
\hline Extremely poor $(<\$ 1$ a day) & 1.25 & 1.06 & 0.87 & 0.94 \\
Poor $(<\$ 2$ per day) & 1.23 & 1.01 & 0.89 & 0.94 \\
Nonpoor $(>2 \$$ per day) & 1.07 & 0.74 & 0.61 & 0.85 \\
\hline \multicolumn{5}{c}{ Source: Own calculations based on ECVH 2001. }
\end{tabular}

\footnotetext{
${ }^{33}$ This does not necessarily mean that they are better off than the average in their new place of residence.
} 


\begin{tabular}{lcccc}
\hline \multicolumn{5}{l}{ Table 5.2: Average Number of Youth per Household Member, 2001 } \\
\hline Income (per capita) & Metropolitan & Urban & Rural & Haiti \\
\hline Extremely poor $(<\$ 1$ a day) & 0.26 & 0.20 & 0.17 & 0.19 \\
Poor ( $<$ \$2 per day) & 0.25 & 0.20 & 0.18 & 0.19 \\
Nonpoor $(>2 \$$ per day) & 0.25 & 0.20 & 0.19 & 0.21 \\
\hline
\end{tabular}

Source: Own calculations based on ECVH 2001.

The nuclear family with a wife, a husband, and two or three children is not a common phenomenon in Haiti. As in other countries, the division of labor is not as economically obvious as in the past since women's opportunity cost of not working increases with an increasing level of education. Education of women and lack of jobs for men lead to marriage being less attractive. Furthermore, in Haiti men are typically involved in a number of unions or have several partners. Polygamy is widely accepted and 8 percent of married men have more than one wife. In fact, 2.4 percent of all married persons live in relationships where the husband has seven or eight wives. This, together with many households being affected by domestic or international migration as described in Section 4, changes the more traditional household into a more vulnerable one containing only one parent or no parents at all. Of all households in Haiti, 53 percent are headed by women. This is the case because husbands have migrated, died, or simply never taken part in the household. Table 5.3 reveals that only slightly more than one out of two children in rural areas live with both parents while just one out of three children is living with both parents in urban areas including Port-au-Prince. More than 30 percent of children are only living with their mother and despite stigma many fathers provide little economic support, leaving the household with a high probability of falling into poverty (World Bank 2002). Moreover, it is common to send children to other households for education and as domestic servants. Slightly more than 8 percent of children aged 5-7 are domestic workers; 59 percent of these are girls (Sommerfelt 2002). Child domestics are an important component in the household composition and social organization, but some children are exploited and exposed to hazardous work. Thus, the laws that protect children to allow them to attend school are not enforced and lack of human capital accumulation places domestic servants at risk. Naturally, domestic servants are not just affected in their childhood, but also disadvantaged as youth or adults. Therefore, measures also need to target children at risk and improve their opportunities later in life.

\begin{tabular}{lcc}
\hline \multicolumn{3}{l}{ Table 5.3: Proportion Living with Parents, 2000 (percent) } \\
\hline Both parents & Urban & Rural \\
Mother only & 38.9 & 53.8 \\
Father only & 33.8 & 24.0 \\
Neither & 7.4 & 5.5 \\
\hline \multicolumn{2}{l}{ Note: Age group 0-14 years. Urban including metropolitan. } \\
\hline \multicolumn{3}{c}{ Source: DHS 2000. }
\end{tabular}


Twenty percent of urban children have neither their father nor mother in their household. Youth who experience the absence of one or both parents tend to fare worse in school than their peers (World Bank 2003). Besides the observed orphans a large number of children also live in the streets. These youth are not likely to be represented in the ECVH household survey, and therefore some of the worst-off youth are not accounted for in the results. Because this very vulnerable group is of obvious concern, more research and data collection in the area are encouraged. Street children are at very high risk of taking part in prostitution or gangs, which they may see as their only escape from isolation and destitution.

In conclusion, a large proportion of youth in Haiti lacks the family support they need. Eighty-six percent of youth find that family disintegration is a very serious problem in Haiti; a shocking 94.6 percent of youth living in the metropolitan area have this opinion. Living without both or with just one parent in the household is likely to have negative effects on a youth's self-esteem and learning abilities. Moreover, a perhaps more important determinant for youth being at risk is whether the household lives in peace and harmony. The antithesis of this, domestic violence and insecurity in general, are examined in detail in Section 6. Optimal family planning is often not achieved, in part because of lack of information. Youth engaging in early unprotected sexual activity may be the beginning of a family, but also the end of it, as HIV/AIDS is widespread.

\section{Risky Sexual Behavior}

The health sector or rather the lack of health services, information, etc. in Haiti is negatively affecting youth. Only 50 percent of youth feel they are in good health and for the cohort aged 35-44 the proportion is merely 26 percent. HIV/AIDS has reached epidemic proportions, with the highest incidence outside Africa. 5.2 percent of persons between the ages of 15 and 19 have HIV/AIDS; men and women are equally affected. As negative outcomes, 210,000 were living with HIV/AIDS and an estimated 23,000 died from AIDS in 1999 alone, thus limiting the society's advancement (UNAIDS 2000). Disturbingly, because 74,000 are expected to have become orphans because of these AIDS-related deaths, intergenerational issues should be of obvious concern (World Bank 2003). Youth undertake high risk behavior by early and frequent unprotected sex with multiple partners. In spite of this and the alarming figures above, only three percent of youth report they have been tested for AIDS; for rural youth the percentage is less than two. Only two out of three youth view AIDS as a serious problem. This may to some extent be explained by lack of knowledge because more than five percent of youth have never even heard of AIDS. Youth in rural areas have nearly twice the incidence as that of metropolitan youth; 6.3 and 3.4 percent, respectively, have heard of AIDS. Prostitution is common for youth in Haiti and places a large group at risk. During the years after these surveys were conducted the situation is expected to have improved somewhat. At a recent UN General Assembly Special Session on HIV/AIDS, ${ }^{34}$ Haiti was recognized for progress in scaling up treatment with support from the Global Fund to Fight AIDS,

\footnotetext{
${ }^{34}$ June 2, 2005, New York Times (Lawrence K. Altman).
} 
Tuberculosis and Malaria. Nevertheless, political commitment remains inadequate and the epidemic is still a major challenge.

Contraceptive use is low in Haiti. Considering the proportion of the population infected by HIV/AIDS, unprotected sexual activity is a major risk factor. Nevertheless, according to the HCVH survey contraceptive use is not as alarmingly low as suggested by some papers. The results indicate that more than 80 percent of youth who are aware of AIDS have taken precautions against it (Table 5.4). Of course this result does not show the proportion of those who have ever had one unprotected sexual encounter, which is likely to be very high. Teen pregnancy is also connected to unprotected sex.

\begin{tabular}{|c|c|c|c|c|}
\hline Age group & Metropolitan & Urban & Rural & Haiti \\
\hline 15-19 years & 88.1 & 78.9 & 71.1 & 76.6 \\
\hline $20-24$ years & 93.4 & 89.4 & 78.3 & 85.4 \\
\hline 15-24 years & 90.9 & 83.0 & 74.0 & 80.5 \\
\hline 25-34 years & 92.7 & 84.6 & 75.8 & 82.8 \\
\hline 35-44 years & 94.3 & 89.1 & 71.3 & 80.6 \\
\hline
\end{tabular}

\section{Teenage pregnancy}

Contributing to Haiti's high fertility rate are teenage mothers who deliver around 8 percent of all births (World Bank 2002). A reason for this high number is that the onset of sexual initiation is earliest in the Caribbean region after that of Africa inside marriage. The LAC average for births to young females was 52 per 1000 females aged 15-19 in 2002. For Haitian teenagers (aged 15-19), the number of births per 1000 females in 2000 was 68.3, 31 percent above the regional average (World Bank 2005a, 2003). Teen pregnancy, as result of early unprotected sexual activity, is generally associated with negative outcomes such as lower education, maternal mortality, limited job opportunities, etc. The regression results in Table 4.5 support this hypothesis because marriage increases the probability of dropping out of school and teenage pregnancy is highly correlated with marriage in Haiti. Causality is likely to not only go from teen pregnancy to low education, but low-educated teens are also predisposed to have children early (Table 5.5). In this regard, Table 5.6 reveals that sexual initiation is closely connected to education. Thus, keeping youth in school would likely reduce HIV/AIDS and teen pregnancies dramatically. Pregnancies and HIV/AIDS disproportionately affect youth from low-income families because they lack information and family counseling. 


\begin{tabular}{lccc}
\hline \multicolumn{4}{l}{ Table 5.5: Age of Females at First Birth by Education, 2000 } \\
\hline Age group & None & Primary & Secondary or higher \\
\hline $20-24$ & 19.9 & NA & NA \\
$25-29$ & 19.7 & 20.4 & NA \\
$30-34$ & 20.0 & 21.4 & 27.2 \\
$35-39$ & 20.4 & 21.6 & 25.6 \\
$40-44$ & 20.7 & 21.7 & 24.9 \\
\hline \multicolumn{4}{c}{ Source: DHS 2000. } \\
\hline \multicolumn{4}{l}{ Table 5.6: Age at Sexual Initiation by Education, 2000 } \\
\hline Age group & None & Primary & Secondary or higher \\
\hline 20-24 & 16.7 & 17.5 & 19.4 \\
$25-29$ & 17.0 & 17.2 & 20.0 \\
$30-34$ & 17.6 & 18.2 & 20.1 \\
$35-39$ & 16.7 & 18.2 & 21.0 \\
$40-44$ & 17.6 & 18.6 & 19.1 \\
\hline \multicolumn{4}{c}{ Source. DHS 2000. }
\end{tabular}

It is important to realize that not all teen pregnancies should be seen as unwanted in order to reduce the occurrence. In Haiti many teen pregnancies are planned because motherhood and the possibility of marriage, which motherhood makes more likely, is perceived as a way of gaining recognition and bringing meaning to life. Other reasons for teen pregnancies include a general view of children as an asset for labor and the fact that abortion is illegal in all circumstances and punishable by three to nine years of imprisonment (World Bank 2002). Because of the strict abortion law some youth may be forced into illegal hazardous abortions that place their lives at risk. In this context, religion is an important opinion maker in Haiti. Catholicism and Voodoo are the main religions besides Protestantism; the former two promote fertility by being against contraception. In fact, when asked: "what is the ideal number of children" 17 percent of married youth answer that this is left to "God's will." With this in mind, it is surprising that 32 percent of married youth aged 20-24 claim they currently use contraception (Table 5.7). It is half as likely that married teenagers use contraception; thus young married females are at high risk of pregnancy. Forty-three percent of single but sexually active teenagers use contraception, which is also far from a desirable level. Metropolitan youth are much more frequent users of contraception than youth in rural areas. In sharp contrast to the reported relatively frequent use of contraception is the fact that 91 percent of youth who have ever been engaged to be married have children and when asked about the ideal number of children 27 percent have no upper limit.

\begin{tabular}{lcc}
\hline \multicolumn{2}{l}{ Table 5.7: Current Use of Contraception, 2000 (percent) } \\
\hline Age group & Married & $\begin{array}{c}\text { Single but } \\
\text { sexually active }\end{array}$ \\
\hline $15-19$ & 16.4 & 42.9 \\
$20-24$ & 32.1 & 36.6 \\
$25-29$ & 31.3 & 40.5 \\
$30-34$ & 32.4 & NA \\
$35-39$ & 31.8 & NA \\
\hline \multicolumn{3}{c}{ Source: DHS 2000. }
\end{tabular}




\section{Security}

\section{Safety}

Feeling safe is important for a person to be able to go to school, work, the market, neighboring communities, towns, and cities, and to have social relations. In Haiti nearly 25 percent of youth do not feel safe in their homes (Table 6.1). A third of youth are afraid of visiting larger cities and more than one out of four fear going to the local market. One out of five considers going to a nightclub or bar to be dangerous while one out of eight of the age cohort 35-44 fears this. The metropolitan area, where over 45 percent of youth reside, is considered to be far more dangerous than rural areas. Variance between rural and urban areas is not found across age cohorts for the entire country; this indicates that not only youth but the entire population feel insecure and specifically so in Port-auPrince. Living in a stressful environment is an obvious risk factor for youth. More than 85 percent of youth concur that crime and insecurity are a very serious problem in Haiti. As a result of the perceived security situation only slightly more than one out of ten youth generally trust other people. Such a fundamental lack of trust in other persons affects youth in various social and economic ways; social networks deteriorate and effective and efficient markets are nonexistent. ${ }^{35}$ Some simply cannot go to school because of a violent environment.

\begin{tabular}{lcccc}
\hline \multicolumn{5}{l}{ Table 6.1: Feeling of Safety in Household. 2001 (percent) } \\
\hline Age group & Metropolitan & Urban & Rural & Haiti \\
\hline 15-19 years & 44.0 & 91.7 & 88.3 & 79.4 \\
20-24 years & 38.6 & 88.1 & 83.8 & 69.6 \\
\hline 15-24 years & 41.1 & 90.2 & 86.6 & 75.2 \\
\hline 25-34 years & 39.4 & 88.7 & 78.9 & 67.7 \\
35-44 years & 40.7 & 81.9 & 81.1 & 70.2 \\
\hline \multicolumn{5}{c}{}
\end{tabular}

\section{Crime and Domestic Violence}

Crime is a serious problem in Haiti: it has long-lasting financial effects on society and erodes human capital development. A general problem for addressing crime and especially domestic violence is the lack of data for the Caribbean. Moreover, problems of underreporting can be serious because of lack of trust in the interviewer or the simple fact that such issues are rarely addressed in public in Haiti; hiding from the truth is one of the main obstacles facing external agencies, as also noted by Moser and Lister (1999).

The LAC regional homicide rate is the highest in the world: 20 homicides per 100,000 , which is twice that of the USA (Ayres 1998). In Haiti, most killings and kidnappings take place in Port-au-Prince. Violence is an integral part of the environment and works as a coping mechanism for unfortunate youth and adults. For poor youth living

${ }^{35}$ In the US a negative relation between crime and schooling is generally observed (Eckstein and Wolpin 1999). 
in the slums, attacks or robberies are a constant threat (Moser and Lister 1999). Eighty percent of violent crimes in the Caribbean are committed by men, the majority of whom is under age 35. The direct costs associated with crime are the costs of lives, incarceration, and physical damage to assets, as well as a number of indirect costs such as foregone earnings, lower investment, and less tourism. Moreover, relations and human and social capital are destroyed (Moser and Bronkhorst 1999).

Domestic violence is a considerable problem in Haiti. Table 6.2 shows the percent of married youth who have experienced specific domestic violence. Violence is mainly committed by men and inflicted upon women; as may be expected women tend to report more violence than men. Table 6.2 reveals that forced sex is the most common (reported) offense in households. It will be extremely difficult to change this because many women do not even know they have the right not to be abused by their husbands (World Bank 2002).

In families with a child in primary school, 20 percent of households reported the wife had been beaten in front of the child. Witnessing violence leads to low ability to confront stressful situations and antisocial and self-destructive behavior because of developmental damage (Barker and Fontes 1996). Data from the US show that 75 percent of juveniles have been abused by family members, more than half come from singleparent families, 60 percent have parents who abuse alcohol or drugs, and a third have a brother who has been imprisoned (Ayres 1998). Therefore, it is crucial to improve conditions for youth in their respective households and neighborhoods, in order to decrease crime and violence in the future.

\begin{tabular}{lcccc}
\hline \multicolumn{5}{c}{ Table 6.2: Domestic Violence Inflicted or Experienced, 2001 (percent) } \\
\hline & Metropolitan & Urban & Rural & Haiti \\
\hline Pushed/grabbed & 7.7 & 5.2 & 5.6 & 5.9 \\
Slapped & 6.2 & 3.0 & 4.6 & 4.6 \\
Thrown things at & 2.1 & 1.4 & 1.6 & 1.6 \\
Kicked & 5.4 & 1.9 & 2.6 & 3.0 \\
Hit with objects & 1.7 & 1.2 & 1.2 & 1.3 \\
Choked & 3.4 & 1.0 & 0.9 & 1.4 \\
Violent behavior & 2.9 & 3.2 & 2.6 & 2.8 \\
Forced sex & 13.8 & 10.0 & 11.4 & 11.6 \\
\hline
\end{tabular}

Source: Own calculations based on ECVH 2001.

An estimation of the impact of individual characteristics on the probability of being out of school was performed in Section 4. More in-depth estimations have been conducted on a smaller sample, including only one randomly selected individual aged 15 or older from each household, and therefore fewer youth are included than in the previous estimations shown. This smaller sample was used because it contains information on a range of potentially significant variables describing health, crime and security issues, drug use, and domestic violence. In order to use as large a sample as possible, youth as household heads are included. ${ }^{36}$

${ }^{36}$ To avoid collinearity, as a result of youth being the household head in around half of the observations, the household head's education has not been included in the models presented. Consequently, 
In addition to the models previously presented on education and unemployment, two similar models are presented in Table 6.3. Model 1 basically includes the same variables as in Table 4.4 on school dropout, but uses the smaller sample. The coefficients have the same signs when the smaller sample is used. The advantage of using this smaller sample is that it contains additional information, allowing the inclusion of indicators for risk factors relevant to identify youth at risk. Model 2 includes such indicators, i.e., one for substance abuse, which will be discussed below, and domestic violence in marriage. Because domestic violence is only observed for married youth, the residual comparison group is all unmarried youth, i.e., also those experiencing domestic violence. Although the interpretation of the findings is not straightforward the results are shown in Table 6.3. It is revealed that being married without experiencing violence still has a statistically significantly positive effect on the probability of dropping out of school. Thus, regardless of the presence of domestic violence, being married increases the probability of leaving school compared to being unmarried. When domestic violence is present in the household the probability of dropping out is higher (but statistically insignificantly so) than among married youth without domestic violence.

In addition it is found that migration has a statistically significant negative effect on the probability of leaving school, thus lending more support to the positive selfselection hypothesis for migrants.

\begin{tabular}{|c|c|c|c|c|}
\hline \multicolumn{5}{|c|}{ Table 6.3: Probability of Youth being Out of School in Haiti, $2001^{37}$} \\
\hline \multirow[b]{2}{*}{ Dropout } & \multicolumn{2}{|c|}{ Model 1} & \multicolumn{2}{|c|}{ Model 2} \\
\hline & Coefficient & $\mathrm{t}$ & Coefficient & $\mathrm{t}$ \\
\hline Age & 0.615 & 1.09 & 0.507 & 0.89 \\
\hline Age squared & -0.010 & -0.69 & -0.007 & -0.50 \\
\hline Metropolitan* & 0.411 & 1.72 & 0.349 & 1.43 \\
\hline Rural* & 0.235 & 1.03 & 0.262 & 1.13 \\
\hline Primary education* & -1.080 & -2.08 & -0.911 & -1.69 \\
\hline Secondary education* & -2.054 & -3.90 & -1.885 & -3.44 \\
\hline Migrated* & -0.311 & -1.60 & -0.355 & -1.79 \\
\hline Married (no violence)* & 1.156 & 4.04 & 1.243 & 4.48 \\
\hline Married (domestic violence)* & & & 1.654 & 4.39 \\
\hline Substance abuse* & & & 0.381 & 1.77 \\
\hline Constant & -7.143 & -1.27 & -6.321 & -1.11 \\
\hline Pseudo $\mathrm{R}^{2}$ & 0.30 & & 0.3 & \\
\hline \multicolumn{5}{|c|}{$\begin{array}{l}\text { Note: No. observations: } 593 .{ }^{*} \text { is a discrete dummy variable; } \mathrm{t} \text { is the test of the underlying } \\
\text { coefficient being equal to } 0 . \text { Substance abuse includes: ever used drugs, know drug user, use alcohol } \\
\text { frequently, and smoke. Domestic violence includes: beat/beaten while pregnant, beaten in front of } \\
\text { child, pushed, slapped, thrown things at, kicked or hit, choked, been violent, and forced sex. } \\
\text { Variables left out: urban, no education, single. In the first model married includes also married } \\
\text { experiencing violence. }\end{array}$} \\
\hline
\end{tabular}

education may catch some of the effect from the household head's education and thereby lead to overestimation of the coefficients (when included, however, the household head's education was found to be insignificantly different from zero).

${ }^{37}$ Gender, family size, family size squared, religion, and indicators for feelings of insecurity and experienced crime also came out statistically insignificantly different from zero. 


\section{Substance Abuse}

Substance abuse and especially drug abuse seem very low (or underreported) in Haiti. Early substance abuse is generally associated with negative effects on work ability, human capital accumulation, health, and also with increasing dropout rates from school (e.g., Chatterji and DeSimone 2005). Because drug trafficking takes place in Haiti, some extent of drug use is to be expected. There are indications that drug trafficking in itself is the root of gang-related crime and violence, while drug use is found to be low compared to Jamaica, for example. Not surprisingly, drug use is concentrated in the capital. In the Port-au-Prince metropolitan area, just 0.6 percent of youth answer that they have tried drugs, while in rural areas a noticeable zero percent use is reported. Given these results, however, it is surprising that more rural Haitian youth claim to be in contact with drug users than do metropolitan youth; this suggests an underreporting of actual use. Results from other countries show that the groups most affected are generally prostitutes and street children. Alcohol is consumed widely in Haiti, but far more by adults than youth; 0.6 percent of youth frequently drink alcohol while 5.1 percent of the age group 35-44 do. The same pattern exists among smokers where 4.5 percent of youth smoke and 16.7 percent of the age group 35-44 do. Again, an underreporting of consumption is likely because of a substantial illegal trade in cigarettes (WHO 2005). Generally, the survey suggests that cigarettes, alcohol, and harder drugs are used less frequently than in comparable countries in LAC, but the reported use is expected to be somewhat conservative. The use of addictive goods increases with age, thus targeting the younger age groups is necessary to keep abuse at a minimum. However, part of the increase in use with age may be a result of higher employment rates among older age groups. Earning an income allows more people to buy cigarettes or alcohol, so information programs are needed regardless of age. More research and data collection are needed in order to expose the impact and extent of substance abuse in Haiti.

Table 6.3 above shows a statistically significant positive effect of including a composite variable named addiction when regressing dropout on a set of characteristics. The variable addiction indicates whether the youth has ever tried drugs, knows drug users, smokes, or drinks alcohol. Thus, these are characteristics for an exposed group at high risk. Although the regression is to be seen as evidence of correlation rather than causality, Chatterji and Desimone (2005) test the causality of heavy drinking on the probability of staying in school by an Ordinary Least Squares (OLS) regression and by use of an instrumental variables (IV) model and establishes causality. Moreover, the results from the OLS estimation are conservative, i.e., the negative effect from drinking is larger in the IV regression than estimated in a simpler model. Drug abuse indicates family problems, minimal parental monitoring, bad reputation, and low attachment to school (ibid.). Thus, the results here as in many prior papers suggest that contact with drugs, alcohol, or cigarettes predispose youth to dropping out of school. 


\section{Conclusion}

Of the approximately 1.6 million youth in Haiti only slightly more than 200,000 are content with their lives. Over 20 percent of a population of 7.9 million is between 15 and 24 years of age in Haiti. To improve Haiti's social and economic situation, youth need attention. This paper examines a number of risk and protective factors predisposing youth to negative outcomes that are costly both for the current generation and with intergenerational effects for future generations as well. By identifying risk factors in areas of poverty, inequality, gender, education, labor market, migration, family, health, and violence and identifying vulnerable groups in respect to these, this paper helps to target initiatives and spending.

Education has significant positive wage returns and acts as a protective factor to preempt negative outcomes. Moving up the educational ladder leads to postponed age at starting a family, improved health, fewer children and more focus on their education, and improved skills and competitiveness in the labor market. In Haiti three out of four are in school at the age of 15 while fewer than half are in school at the age of 19. Illiteracy has been falling and average years of schooling have been increasing over recent decades, but still less than 50 percent of youth have completed more than primary education.

Of the large proportion of youth not attending school most enter the labor market (56 percent), many of them at a premature age. However, the 44 percent of inactive youth are not likely to be idle, but rather to be working in the household or fields or engaging in illegal activities. For youth entering the labor market, unemployment is an enormous obstacle in the transition to independence and adult status; 47 percent are unemployed. Gender determines to a large extent the work sector for youth; working male youth are most likely to work in agriculture while female youth tend to work in the service sector.

The impact of individual characteristics on the probability of dropping out of school and the probability of being unemployed or inactive for youth not attending school were estimated to reveal vulnerable groups. Female youth clearly need attention because this group is more likely to drop out of school and also to be unemployed or inactive than their male peers. Furthermore, being married has negative effects on attending school and on being unemployed or inactive. This follows because implications for getting married are men being breadwinners and women having children or perhaps a newly established household to take care of. Role models, hereditary abilities, and contacts in the form of the household head were found to be decisive factors for keeping youth in school and to some extent for their finding employment. Surprisingly, higher levels of education do not lead to an increased probability of employment, most likely because of increased search time, higher reservation wage, and low quality of education. Creating job opportunities and directing the education system more toward skills demanded in the labor market is necessary to avoid frustration among youth.

Major regional differences and lack of opportunities have led to extensive use of migration as a coping mechanism, with urban areas receiving the vast majority of

migrants. Moreover, education contributes significantly to migration because higher 
levels of teaching facilities are only located in urban areas, mainly in Port-au-Prince. Thus, migration was found to have a positive impact on the probability of employment. Although migrants are better educated and appear to be positively self-selected compared to those who stay behind, migration may also lead to stressful situations for youth affected. For example, the high level of migration has affected the family structure in Haiti. More than half of the households are headed by a female.

HIV/AIDS is at an epidemic level in Haiti. Thus, low contraceptive use in connection with a low sexual initiation age and multiple partners is a major risk factor for youth who may become infected with HIV/AIDS. However, HIV/AIDS treatment has been scaled up in recent years and the situation may now be better than the numbers suggest. Furthermore, teenage mothers deliver some 8 percent of all births, predisposing both themselves and their children to low educational attainment, low income, and social exclusion. More information, education, and services in such vital areas are necessary to stop the vicious circle.

Crime and violence have negative impacts on youth both economically and socially; efficient markets are nonexistent and social relations deteriorate. Youth in the metropolitan area experience far higher levels of crime, violence, and insecurity than in the rest of Haiti. Besides their fear of experiencing crime and violence when they leave the household, many are also exposed to domestic violence and abuse. In 20 percent of households with a child in elementary school, the child has witnessed violence, an experience likely to lead to long-term developmental damage. It was found that married youth who experience domestic violence are much more likely to leave school than unmarried youth and more likely to drop out than married youth without domestic violence, keeping other things constant.

Clearly related to crime and (domestic) violence is drug abuse, including hard drugs and alcohol and tobacco, as an indicator for relations to certain social groups. To some surprise the use of such goods was found to be low both in rural and urban Haiti, but increasing with age. Even though results are suspected to be somewhat underestimated and underreported, this is good news. Because drugs are found to have a statistically significant positive impact on the probability of youth dropping out of school, it is important to keep abuse at a low level through information and creation of opportunities in combination with fighting drug trafficking and distribution.

Not all aspects and details affecting youth have been covered in this paper and more research is therefore required. Future research on youth and on the labor market in general should consider the gender issue in greater detail. In regard to the labor market, it is important to establish the link to education. In this regard, it would be interesting to obtain more information on the quality of schooling and the coordination between supply of education and demand in the labor market.

The lack of reliable data spanning a number of years is a clear obstacle for any research relating to Haiti. Therefore, consistent data collection in line with the ECVH is encouraged to allow an analysis of time series, panel data, and the evolution in different 
indicators. In addition, expanding the surveys would allow more in-depth analyses. For example, more information could expose the social impacts of migration and remittances or of missing a father or both parents. Furthermore, domestic violence and street children are left out of most analyses, but youth who experience domestic violence or live in the streets are in obvious need of help and guidance; further research and data collection on these groups are invited. Moreover, substance abuse and its extent require far more investigation in order to understand the impact on social and economic aspects. It is important to examine and better understand issues associated with taboos, such as drugs and domestic violence, in order to significantly improve the future for Haitian youth.

Estimating the cost of not investing in youth would be a great challenge, but could also be extremely useful to convince policy makers to invest in children and youth, for example, through prevention programs (see appendix) to avoid negative outcomes rather than being forced to invest in attention programs when failure is directly observed in the forms of crime and violence. The appendix delineates a framework for analyzing and helping youth at risk and outlines a range of possible programs to improve the situation and create opportunities for youth. 


\section{References}

Ayres, Robert L. (1998) "Crime and Violence as Development Issues in Latin America and the Caribbean". World Bank Latin America and Caribbean Studies.

Barker, Gary and Fontes, Miguel (1996) "Review and Analysis of International Experience with Programs Targeted on At-Risk Youth”. LASHC Paper Series No. 5. World Bank.

Becker, Gary S. (1973) “A Theory of Marriage”. Journal of Political Economy. Part I. Vol. 81. No. 4. pp. 813-846.

Chatterji, Pinka and DeSimone, Jeff (2005) “Adolescent Drinking and High School Dropout”. NBER. Working paper. No. 11337.

Chiswick, Barry R. (1999) “Are Immigrants Favorably Self-Selected?”. The American Economic Review, Vol. 89, Issue 2, pp. 181-185.

DHS (2000) “Demographics and Health Surveys”. http://www.measuredhs.com/.

Eckstein, Zvi and Wolpin, Kenneth I. (1999) “Why youth Drop Out of High School: The Impact of Preferences, Opportunities, and Abilities”. Econometrica. Vol. 67. No. 6. pp. 1295-1339.

Fitzpatrick, Kevin M. (1997) “Fighting Among America's Youth: A Risk and Protective Factor Approach”. Journal of Health and Social Behavior. Vol. 38. No. 2. pp. 131148.

Heckman, James J. and Singer, B. (1984) "A Method for Minimizing the Impact of Distributional Assumptions in Econometric Models for Duration Data". Econometrica. Vol. 52. No. 2. pp. 271-320.

HLCS (2003a) “l'Enqueête sur les Conditions de Vie Haïti”. HLCS (IHSI).

HLCS (2003b) “4eme Recensement Général de la Population et de L'Habitat - Résultats Préliminaires”. HLCS (IHSI).

Jiménez, Emmanuel Y. (2005) “Development for, and by, the Next Generation”. Briefing on World Development Report 2007. World Bank. Washington. DC.

Justesen, Michael (2004) “Active Labour Market Measures in Denmark - A Duration Data Analysis with Immigrants in Focus”. University of Aarhus. Denmark.

Katz, Lawrence F. (1986) "Efficiency Wage Theories: A Partial Evaluation”. Working Paper No. 1906. NBER. 
La Cava, Gloria; Clert, Carine and Lytle, Paula (2004) "Investing in youth Empowerment and Inclusion: A Social Development Approach”. Social Development Papers. No. 60. World Bank.

Mortensen, Dale T. (1986) “Job Search and Labor Market Analysis”. In O. Ashenfelter and T. Layard eds. "Handbook of Labor Economics". North-Holland. Chapter 15. pp.849-919. Amsterdam.

Moser, C and Lister S. (1999) "Violence and Social Capital: Proceedings of the LCSES Seminar Series, 1997-98”. Sustainable Development Working Paper No. 5. World Bank. Washington. DC.

Moser, Caroline and van Bronkhorst, Bernice (1999) "Youth Violence in Latin America and the Caribbean: Cost, Causes, and Interventions". Sustainable Development Working Paper No. 3. World Bank. Washington. DC.

Salmi, Jamil (2000) “Equity and Quality in Private Education: the Haitian paradox". Compare. Vol. 30. No. 2.

Saravi, Gonzalo A. (2002) "Youth and Social Vulnerability: Becoming Adults in Contemporary Argentina”. Ph.D. dissertation. University of Texas at Austin.

Saygili, Seref (1998) "Is the Efficiency Wage Hypothesis Valid for Developing Countries? Evidence from the Turkish Cement Industry". Studies in Economics 9810. Department of Economics. University of Kent.

Schneidman, Miriam (1996) “Targeting At-Risk Youth”. LASHC Paper Series. No. 2. World Bank. Washington. DC.

Severe, Patrice et al. (2005) "Antiretroviral Therapy in a Thousand Patients with AIDS in Haiti”. The New England Journal of Medicine. Vol. 353. No. 22. pp. 2325-2334.

Sommerfelt, Tone (2002) “Child Domestic Labour in Haiti”. Fafo Institute for Applied International Studies.

UNAIDS (2000) “Condom Social Marketing: Selected Case Studies”.

USAID (2004) “IDEJEN - Haitian Out-of-School Youth Livelihood Initiative”. Activities Report, October 2003 - December 2004.

UNDP (2002) “La Situation Ěconomique et Sociale D 'Haiti en 2002”.

Verner, Dorte (2005) “Making Poor Haitians Count”. World Bank. Washington. DC.

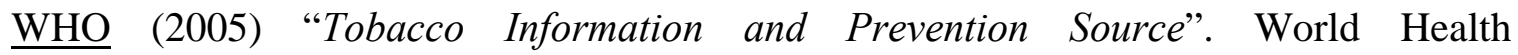
Organization. http://www.cdc.gov/tobacco/who/haiti.htm. 
Wolfowitz, Paul D. (2005) "Charting a Way Ahead: The Results Agenda". Annual meetings address. World Bank. Washington. DC.

World Bank (2005a) “Youth at Risk in Brazil”. Washington. DC.

World Bank (2005b) “Haiti Social Protection Policy Brief”. Haiti Social Protection Report. Washington. DC.

World Bank (2005c) “First Year of Haiti's Interim Cooperation Framework Achievements". Washington. DC.

World Bank (2005d) “World Bank - Youth in Operations 2005: Trends and Highlights”. Washington. DC.

World Bank (2005e) “Children \& Youth: A resource Guide for World Bank Staff”. Washington. DC.

World Bank (2005f) “Dominican Republic Poverty Assessment: Achieving More ProPoor Growth”. Report No. 32422-DO. Washington. DC.

World Bank (2005g) “World Development Indicators”. Washington. DC.

World Bank (2004) “World Development Indicators”. Washington. DC.

World Bank (2003) “Caribbean Youth Development”. A World Bank Country Study. Washington. DC.

World Bank (2002) "A Review of Gender Issues in the Dominican Republic, Haiti and Jamaica”. Report No. 21866-LAC. Washington. DC. 


\section{Appendix}

The need for opportunities and services differ from youth, who live with both parents and attend school, to unemployed poor youth, who live alone or with a single parent. In order to suggest youth programs a three tiered model by Barker and Fontes (1996) is adopted. Possible programs, which follow this model, are given below. In the model risk is divided into three components, but instead of emphasizing the distance or contact from youth to risk, the level of risk is in focus. Causality does not necessarily go directly from I through III, but the components are obviously strongly associated. The components are:

I. Youth in primary risk

This group includes youth, who negatively affected by a general risk such as poverty or a violent neighborhood. The risk may be of youth dropping out of school or in other ways affecting their future well-being because of environmental, familiar or social factors. Negative outcomes of such risk (e.g., violence, drug abuse or school dropout) cannot yet be identified at this stage. Poor school performance and aggressive behavior are examples of indicators for this group.

\section{Youth in secondary risk}

Moving from a general risk to a specific risk, youth can be observed at risk of, for instance, school dropout (poor performance, working at an early age, nonattendance), personal risk (delinquency, gang membership or victim of abuse or neglect) or being part of a household with high risk of e.g., abuse (high unemployment, single teenage parent, substance abuse, history of violence or child abuse or neglect, gang membership in family, and other stressful situations). Being in such a group, youth are at direct risk of harmful situations, but are still connected to their household to some extent.

\section{Youth at tertiary risk}

This group of youth is suffering from identified negative outcomes such as sexual abuse, teen pregnancy or life in the streets. In this situation, connections to family and institutions have been severely weakened.

This framework stresses that attention should not only be focused on for example identified negative outcomes as described in III, but instead on a continuum of all three risk levels. Literature has shown the cost for society is far higher when focusing on tertiary risk than when intervening at earlier stages. This is the case because of the direct costs of rehabilitation programs, but also from a loss of productivity or for instance lower tourism, which result from youth unemployment, crime, violence, and health issues.

In past decades, focus has mainly been on tertiary intervention i.e. programs directed toward treating negative outcomes such as delinquency, school dropout, teenage pregnancy or homelessness. Such measures remain necessary, but been have proven costly and often ineffective. A good example of this is clinics against drug addiction, which are very expensive (per treated individual) and have low success rates (high 
recidivism). Therefore, primary and secondary prevention and protection programs have become more attractive as they intend to prevent negative outcomes (Moser and Bronkhorst 1999). For instance, using an already established contact (e.g., school) to inform youth about drugs is less costly than drug clinics ${ }^{38}$ and may keep potential drug abusers from ever trying drugs. The problem with such programs is to identify and reach the most vulnerable (e.g., youth out of school) as early as possible.

Many youth related programs in LAC are multisectoral and generally focus on preparing youth to be productive members of the society (e.g., World Bank 2005d). This more holistic approach will also be beneficial for Haiti and the following suggestions for intervention should therefore not be seen as distinct initiatives but ideally be integrated. Heterogeneity among youth means it is important to focus on a number of different areas simultaneously and therefore the World Bank needs to coordinate and work with NGOs and other donor agencies to utilize each organization's expertise to increase the standard of living and well-being in Haiti for youth and the population as a whole. As little data exist on program evaluation in Haiti, it is important to monitor, follow up, analyze, and evaluate effects as youth programs are implemented.

When considering programs to implement successfully, it is necessary to bear in mind a prerequisite of security and stability. Thus the implementation of the programs is conditioned on the recent reduction in violence and disorder to increase citizen confidence in new initiatives from international organizations and the government.

\section{Primary prevention programs}

Primary intervention is directed toward prevention of negative outcomes. As shown, health, education, family, and labor market components among others are extremely important to avoid negative outcomes. At the macro level poverty alleviation and equality are the main issues to improve possibilities for youth. To allow and support such improvements laws need to be updated and enforcement to be upgraded to provide equality, security, and trust in Haiti. Furthermore, focus should not only be directed at youth but also the environment, family, local institutions, social norms, etc. For instance, the use of mass media to change norms and supply information is possible as nearly one in three watches TV and two out of three listen to radio at least once a week in Haiti.

At a structural level the most important programs based on the analysis above target school dropout and prevent repetition. Such programs need to aim for increased quality of and easier access to schools. As World Bank president Wolfowitz argued at the 2005 annual meetings address: "We cannot just count the number of schools... It is also about the quality of the curriculum... We must address both the qualitative as well as the quantitative challenges which deny opportunities for the poor" (Wolfowitz 2005). Therefore, education of teachers, improved infrastructure, better equipment, and provision of school meals are keys to development. In addition more schools to reduce class sizes and subsidies either paid to the school to lower tuition fees or to the families

\footnotetext{
${ }^{38}$ Besides the direct costs of a clinic are also costs of crime and violence, increased police attention etc. connected with drug abuse.
} 
for sending youth to school would increase school attendance, and lower school dropout, and thus create protective factors and reduce negative outcomes. A number of other donors are focusing on the supply side of schooling. Therefore, the World Bank should use its experience and expertise on improving the demand side. Subsidies in form of conditional cash transfers have been shown to have positive effects on poverty as well as human capital formation (World Bank 2005b) and the same impact is expected in Haiti if a similar program is implemented.

Health improvement should be a main component of prevention programs. Schools can be used as a vehicle to inform youth on health issues such as contraception to avoid pregnancy or sexually transmitted diseases. World Bank (2005a) finds overwhelming evidence of effects of school based programs. Unfortunately, the schooling system in Haiti is overburdened and on that background results may be limited. Implementation of school based programs needs careful coordination with general education policy. Especially in regard to early unprotected sexual activity and HIV/AIDS information is needed in Haiti (Global Health Council ${ }^{39}$ ). Fortunately, a number of initiatives has already been set up, and as mentioned in Section 5 awareness has increased (World Bank 2005c, UNAIDS 2000). Yet, all program services related to contraceptive use need to cover not just youth in school, females or the married but all youth i.e., also to include dropouts, males, and singles to involve everyone in the solution and seek to change social norms.

Youth unemployment is a major problem in Haiti. Possible interventions include scaling up workfare programs, which are currently supported by the LICUS Trust Fund in order for youth to gain experience and to act as a screening tool for the employer. Also, work related vocational training to gain more employee specific skills would be effective programs. Even though experiences with workfare and on the job training is mixed in welfare states (e.g., Justesen 2004) it is more likely impacts will be positive in Haiti as the need for basic work related skills is higher. Furthermore, entrepreneurial capacity building and micro-loans will increase opportunities for out of school youth. Some donor agencies have provided some micro-lending opportunities in Port-au-Prince, while it has not been possible in rural areas. Job creation programs have also been introduced, but not with youth as a specific target group. When targeting youth for employment it is important to prioritize school for the youngest and weighting full-time employment increasingly with age.

Youth centers, which prove vocational training, job referral, health services, counseling, and cultural activities, have been found positive in Caribbean countries (Ayres 1998). Such centers may be successfully set up in Port-au-Prince and other large cities while sparsely populated rural areas are harder to cover. In rural areas, churches, community groups or schools can be used to integrate youth socially and motivate them to be less destructive by providing opportunities and support. The results in Section 4 showed that positive role models are extremely important in keeping youth in school.

\footnotetext{
${ }^{39}$ http://www.globalhealth.org/sources/view.php3?id=962.
} 


\section{Secondary prevention programs}

Secondary prevention programs distinguish from primary programs by targeting more specifically identified youth at risk and optimally adapting to their needs. An objective of secondary programs is to provide support in order to avoid the costs and time required for tertiary attention programs. A problem with specific identification is the difficulty in reaching those at risk as households may want to hide the fact that youth in the household are at risk of for instance abuse or of involvement in prostitution. Secondary prevention programs aim to work against abuse of youth, deter prostitution, and to create possibilities for education, jobs, and cultural activities.

La Cava et al. (2004) suggest increasing empowerment of youth at risk through formal education (avoiding school dropout). Furthermore, non-formal education also leads to empowerment. Such education includes training in life and livelihood skills as a prevention program. Life skills training consists of guidance in social skills, decision making, leadership, stress management, creativity, and in learning to deal with conflicts and emotions. Livelihood improvement includes training in support and counseling in job search, interviews, and guidance and support toward self-employment. In addition, home visitation counseling, health and social services such as substance abuse counseling should be part of the programs (Barker and Fontes 1996). Currently small-scaled nonformal education programs are run by USAID with the main objective of improving living conditions for out of school youth through basic education (USAID 2004). However, more support is needed. Mentoring by responsible older peers has been identified as an important incentive to stay in school. Mentoring could be by adults, but also to integrate youth to support youth at risk has been successful in LAC countries. To help street children, supply of mobile libraries, education in health and sexually related issues, recreational events, and training of parents will have significant effects.

To focus more on the individual, identification, sustained counseling, monitoring, and parental involvement are required (Schneidman 1996). Specifically, as youth at secondary risk is likely to still be in contact with their family, it is important to include the family if possible in creating incentives for youth at risk i.e., helping the family work as caregivers.

For a group of females, with a combination of risk factors increasing the prevalence of prostitution such as poverty, school dropout or not being allowed or able to attend school, unemployment and sexual abuse in the household or living in a disintegrated family, a solution could be to set up female collectives. By providing education and cultural activities, related to abuse and prevention of ending up in prostitution, negative outcomes may be avoided.

Creating jobs for unskilled youth at a low wage will attract poor school dropouts and by incorporating a feature of basic education or training as part of the work an otherwise negative human capital development curve can be bent and negative outcomes avoided. In fact, the World Bank has in the mid-1990's successfully implemented similar programs, however, not targeting youth. Most youth in Haiti work in the informal labor 
market, thus improving working conditions and income generation in the informal sector is important to reduce risk factors for working youth. For youth out of school, programs, which teach a level equivalent to primary education, but also which emphasize life skills as described above and workforce behavior, have been launched (World Bank 2005c). Other ways out of unemployment and inactivity is to set up production workshops for youth to learn a trade.

\section{Tertiary attention programs}

Tertiary attention programs target youth who suffer negative outcomes i.e., youth who are in need of rehabilitation or need to be removed from a harmful situation. Due to primary programs often being more costly, time-consuming, and more intensive than secondary programs, governments are less likely to be interested in borrowing for such programs and the programs are also less specific to the World Bank - yet they remain necessary and important. As prevalence of youth at tertiary risk is higher in certain groups than others (e.g., drug users) it is important programs are designed to match the needs for these groups. Tertiary programs may reach the affected group by drop-in counseling centers, through schools, health services or group homes where e.g. youth exposed to domestic abuse can be placed. Furthermore, contact with medical staff, probation officers, and mental health technicians could decrease recidivism. For example, these programs could improve the situation for prostitutes and youth living in the streets by providing vocational training, assisting pregnant girls to continue education, placing them in jobs etc.

Tertiary attention programs also include negative incentives such as incarceration, boot camps, to increase the number of police officers in the streets, and stiffening sentences (Ayres 1998). The extreme level of crime and violence in Haiti requires an extraordinary effort by the UN Stabilization Mission in Haiti (MINUSTAH) and the Haitian national police. Security is a key requirement for any development in Haiti. In particular control needs to be regained over slum areas (especially Cite Soleil in Port-auPrince) to, for example, initiate urban upgrading programs.

Treating acute health issues would be extremely expensive, but also extremely important for the Haitian government. Basic care treatment of HIV/AIDS has been estimated to cost US\$12 per capita, which corresponds to an increase of 67 percent in health expenses (World Bank 2003). A recent study of AIDS treatment in Haiti described the program as extremely successful assisting 1004 AIDS patients, with positive results on the same level as for patients in the US. Costs for the program were high (US\$1,600 per patient per year), but it was proven a rapid and effective large scale therapy is possible in Haiti in spite of poverty and political unrest (Severe 2005). Subsidizing health service fees to the poor is generally regarded as an effective way of improving health indicators, but distinguishing people in need from those in less need requires the building of capacity and expertise in Haiti. 